\title{
Structural Examination of Ring-Closing Metathesis-Derived 15- Member Macrocycles as Grb2 SH2 Domain-Binding Tetrapeptide Mimetics
}

\author{
Fa Liu ${ }^{1}$, Karen M. Worthy ${ }^{2}$, Lakshman K. Bindu ${ }^{2}$, Robert J. Fisher ${ }^{2}$, and Terrence R. Burke \\ $\mathrm{Jr}^{1^{*}}$ \\ 1Laboratory of Medicinal Chemistry, CCR, NCI, NIH, Frederick, MD 21702 \\ 2 Protein Chemistry Laboratory, Advanced Technology Program, SAIC-Frederick, Frederick, MD
}

\begin{abstract}
Ring-closing metathesis (RCM) was employed to join carboxy-terminal alkenyl glycine side chains together with vinyl- and allyl-functionality appended to the $\beta$-methylene of amino-terminal phosphotyrosyl (pTyr) mimetics. This required the synthesis of a variety of new pTyr mimetics, including a novel aza-containing analogue. Many of the resulting 15-member macrocyclic tetrapeptide mimetics exhibited low nanomolar Grb2 SH2 domain-binding affinities in spite of the fact that differing ring junction stereochemistries and geometries of the RCM-derived double bond were employed. The finding that significant latitude exists in the structural requirements for ring closure, may facilitate the development of therapeutically-relevant macrocyle-based Grb2 SH2 domain-binding antagonists. The synthetic approaches used in this study may also find application to peptide mimetics directed at other biological targets.
\end{abstract}

\section{Introduction}

Development of high affinity protein-binding ligands ultimately entails the complimentary alignment of functional groups between the binding molecule and the target protein. Restricting ligand conformational flexibility as one traditional approach toward affinity enhancement ${ }^{1-5}$ has been based on the rationale that increased free energy may result from reducing entropy penalties incurred during binding. ${ }^{6} \mathrm{Grb} 2 \mathrm{SH} 2$ domains are docking modules found in a variety of cellular signaling pathways that represent potentially important therapeutic targets. ${ }^{7}$ These domains are characterized by their preferential recognition of "pTyr-Xxx-Asn-Yyy" sequences in type I beta turns. ${ }^{8}$ Accordingly, the design of Grb2 SH2 domain-binding inhibitors has focused on variation of the individual amino acid residues within the short recognition sequence as well as on induction of turn-geometries within the peptide secondary structure. ${ }^{9}$ This has offered an important target for application of novel chemistries to the design of new peptide mimetics. In our own program to develop Grb2 SH2 domain binding antagonists, a central theme has been global restriction of overall peptide conformation through ring-closing olefin metathesis (RCM) macrocyclization. A unique feature of our approach has been the joining of

To whom correspondence should be addressed at: Laboratory of Medicinal Chemistry Center for Cancer Research, National Cancer Institute National Institutes of Health, NCI-Frederick P.O. Box B, Bldg. 376 Boyles St. Frederick, MD 21702-1201 Tel: (301) 846-5906; Fax: (301) 846-6033 e-mail: tburke@ helix.nih.gov.

Supporting Information Available: Synthetic procedures for compounds 4 and 5, ${ }^{1} \mathrm{H}$ NMR spectra of compounds 7 - 9, 11, 13 - 15, 17, $19-24$ and $2 \mathrm{c}-2 \mathrm{~g}$ and ${ }^{13} \mathrm{C}$ NMR spectra of compounds $5,7-9,11,13-15,17,19,2022-24$ and $2 \mathrm{e}-\mathbf{2 g}$. This material is available free of charge via the Internet at http://pubs.acs.org. 
C-terminal alkenyl subsituents onto vinyl- and allyl-functionality appended to the $\beta$-methylene of $N$-terminal pTyr mimetics. ${ }^{10-13}$

The open-chain peptide $\mathbf{1}\left(\mathrm{K}_{\mathrm{D}}=5.6 \mu \mathrm{M}\right)^{14}$ represents a low micromolar affinity starting point for exploring the application of RCM macrocyclization within a unified family of Grb2 SH2 domain-binding inhibitors (Figure 1). Earlier we reported $\mathbf{2 a}\left(\mathrm{K}_{\mathrm{D}}=23 \mathrm{nM}\right)$ and $\mathbf{2 b}\left(\mathrm{K}_{\mathrm{D}}=55\right.$ $\mathrm{nM})$ as the first members of this genre of analogues. ${ }^{14}$ Compounds $\mathbf{2 a}$ and $\mathbf{2 b}$ share a common 14-member macrocyclic core in which the respective RCM-derived ring-closing segments consist of an $11 E$-propenyl chain joined in (10S)-configuration to the lower pTyr mimetic residue with upper ring junctions configured as either (14S) (for 2a) or (14R) (for $\mathbf{2 b}$ ) (segments $\mathrm{X}$, Figure 1). ${ }^{14}$ Macrocycles $\mathbf{2 a}$ and $\mathbf{2 b}$ present a novel template for the design of $\beta$-bend peptide mimetics. However, to date there has been little elucidation of structural requirements in the ring-closing segment needed for high affinity binding. To further explore the effects of structural variation in this region, analogues were designed to enlarge the macrocycle ring size (2c); reverse the stereochemistry of the $\mathrm{C} 10$ ring junction (2d), utilize Z-geometry at the alkenyl bond (2e); replace the $\mathrm{C} 10$ ring junction with an aza-center $(\mathbf{2 f})$ and reverse the stereochemistry of the $\mathrm{C} 9$ carboxymethyl subsituent $(\mathbf{2 g})$.

\section{Results and Discussion}

Synthesis of target macrocycles $\mathbf{2 c}-\mathbf{2 g}$ required preparation of the building blocks shown in Figure 2. The upper ring junction-forming (1-naphthyl)methylamido tripeptide $\mathbf{4}$ was obtained by solid-phase techniques using commercially-available $(S)-N$-Fmoc-allylglycine as previously reported. ${ }^{14}$ The tripeptide 5 was obtained in similar fashion using $(S)$ - $N$-Fmoc-(3butenyl)glycine (3), ${ }^{15}$ which was prepared from the corresponding $N$-Boc $O$-(tert-butyl) ester derivative. ${ }^{16}$ The lower ring junction-forming components consisted of pTyr mimetics 6 -9. Enantioselective synthesis of the vinyl-containing $\mathbf{6}$ was achieved using oxazolidinone chiral auxilliary induction as previously reported. ${ }^{11}$

Preparation of the 2-propenyl-containing $\mathbf{7}$ proceeded from the known $\mathbf{1 0}$ through $\mathbf{1 1}$ in a fashion similar to that used to synthesize 6 (Scheme 1). ${ }^{11}$ Construction of the epimeric pTyr mimetic 8, having $(R)$-stereochemistry at the site of 2-propenyl attachment, was achieved starting with the enantiomer of $\mathbf{1 0}$ (compound 12) and involved hydrolysis of the initial $(R)$ phenyloxazolidinone to yield the free acid (13) followed by re-derivatization to $\mathbf{1 4}$ with the $(S)$-phenyloxazolidinone (Scheme 2). Alkylation in the desired (S)-configuration was achieved to yield 15, which was converted to the free acid $\mathbf{8}$.

Synthesis of the aza-containing pTyr mimetic 9 began with the Pd-catalyzed coupling of allylamine with the known $\mathbf{1 6}^{17}$ to yield the secondary amine $\mathbf{1 7}$ (Scheme 3). ${ }^{18}$ This was subjected to a second alkylation using the $\alpha$-bromoacetylated Evans oxazolidinone $\mathbf{1 8}^{19}$ to give the chiral intermediate 19. Stereoselective $(R)$-introduction of the carboxymethyl ester using tert-butyl $\alpha$-bromoacetate and NaHMDS in THF $\left(-78^{\circ} \mathrm{C}\right.$, then room temperature) gave 20, which was hydrolyzed to the desired aza-containing 9.

Coupling of the upper ring junction-forming tripeptides $(\mathbf{4}$ or $\mathbf{5})$ with the appropriate protected pTyr mimetics (6-9) gave the open-chain metathesis substrates 21 - 24 (Scheme 4). Due to the sterically crowded environment of the $N$-terminal $\mathrm{Ac}_{6} \mathrm{c}$ residue, satisfactory coupling yields required the use of active ester methodology [1-(3-dimethylaminopropyl)-3-

ethylcarbodiimide $\cdot \mathrm{HCl}(\mathrm{EDC} \cdot \mathrm{HCl})$ and 1-hydroxy-7-azabenzotriazole (HOAt)] in DMF at 50 ${ }^{\circ} \mathrm{C}$ for 36 h. ${ }^{11,14}$ Ring-closing metatheses of the tert-butyl-protected peptides $\mathbf{2 1}-\mathbf{2 4}$ were conducted in refluxing $\mathrm{CH}_{2} \mathrm{Cl}_{2}$ using commercially available (Aldrich) Grubbs secondgeneration catalyst $\left[\left(\mathrm{PCy}_{3}\right)\left(\operatorname{Im}(\mathrm{Mes})_{2}\right) \mathrm{Ru}=\mathrm{CHPh}\right] .{ }^{20}$ The crude metathesis products were directly deprotected (aqueous TFA in the presence of triethylsilane) prior to HPLC purification 
to yield the final products $(\mathbf{2 c}-\mathbf{2 g})$ (Scheme 4). The lower yields of final products $\mathbf{2 c}(12 \%)$ and $\mathbf{2 d}(30 \%)$ relative to $\mathbf{2 e}(50 \%)$ and $\mathbf{2 f}, \mathbf{g}(56 \%)$ may reflect the sensitivity of RCM reactions to environmental factors resulting from differences in stereochemisties and substrate geometries. The $E$-geometry was obtained in all cases except for $\mathbf{2 e}$, where only the Z-geometry was isolated. This may reflect a different relative spatial positioning of the two terminal double bonds on the beta-turn scaffold of the RCM precursor 22. Also of note, treatment of the crude aza-containing RCM product $\mathbf{2 4}$ under acidic conditions resulted in partial epimerization at the pTyr mimetic $\alpha$-position to yield the $(R)$-containing $2 \mathrm{~g}$ in a $1: 5$ ratio relative to the nonepimerized $\mathbf{2 f}$. The stereochemistry of $\mathbf{2 g}$ was confirmed by synthesis using the racemic form of pTyr mimetic 9.

\section{Conclusions}

Surface plasmon resonance was used to determine $\mathrm{K}_{\mathrm{D}}$ values for the direct association of ligands in solution to chip-bound Grb2 SH2 domain protein. We had previously shown that for the 14-member parent macrocycle reversal of the upper ring junction from $(S)$ to $(R)$ configuration was well tolerated $\left[(14 S)-2 \mathbf{a}, \mathrm{K}_{\mathrm{D}}=22.7 \pm 0.5 \mathrm{nM} ;(14 R)-\mathbf{2 b}, \mathrm{K}_{\mathrm{D}}=55 \pm 1.0 \mathrm{nM}\right.$, Table 1]. ${ }^{14}$ In the current study we found that adding a methylene spacer to the ring-closing segment of 2a had no effect on binding affinity $\left(2 \mathbf{c}, K_{D}=20 \pm 5 \mathrm{nM}\right)$. Analogue $2 \mathbf{c}$ presents a 15-member ring size, which is the same as related high affinity RCM-derived macrocycles that lack an amino acid residue at the pTyr mimetic +3 position. ${ }^{11,21}$ Reversal of the lower ring junction stereochemistry in $2 \mathbf{c}$ from $(10 S)$ to $(10 R)$ resulted in only a modest loss of binding affinity $\left(\mathbf{2 d}, \mathrm{K}_{\mathrm{D}}=70 \pm 24\right)$. When considered with previous data, ${ }^{14}$ this indicates a relative stereochemical insensitivity at either the upper or lower ring junctions for binding to Grb2 SH2 domains. In contrast, introduction of an aza-center at the lower ring junction resulted in an order-of-magnitude loss of binding affinity $\left(\mathbf{2 f}, \mathrm{K}_{\mathrm{D}}=287 \pm 64 \mathrm{nM}\right)$. This may have been due to unfavorable interaction of the Grb2 Arg67 residue with the cation resulting from 10-aza protonation. A further dramatic loss of affinity occurred by reversal of the pTyr mimetic carboxymethyl configuration from $(9 S)$ to $(9 R)\left(2 \mathrm{~g}, \mathrm{~K}_{\mathrm{D}}>10,000 \mathrm{nM}\right)$. This may be attributed to loss of important interactions between the $\alpha \mathrm{A} 2 \mathrm{Arg} 67$ residue and the pTyr mimetic carboxylic acid. ${ }^{22}$ While $\mathbf{2 f}$ and $\mathbf{2 g}$ contained highly unfavorable alterations, changing the position and geometry of the metathesis-derived double bond in $2 \mathbf{c}$ from $11 E$ to $12 Z$ was well tolerated $\left(\mathbf{2 e}, \mathrm{K}_{\mathrm{D}}=38 \pm 15 \mathrm{nM}\right)$.

Although much work has been done examining structural variation of individual amino acid residues in relation to $\mathrm{Grb} 2 \mathrm{SH} 2$ domain-binding affinity, much less has been done to delineate effects of global conformational constraint. ${ }^{9}$ The current study has demonstrated that within a family of RCM-derived macrocycles typified by $\mathbf{2}$, considerable diversity in size, composition and ring junction stereochemistry is compatible with high affinity $\mathrm{Grb} 2 \mathrm{SH} 2$ domain binding. In contrast, the stereochemical requirements at the pTyr mimetic $\alpha$-position appear to be more demanding. The finding that significant latitude exists in the structural requirements for ring closure, may facilitate the development of therapeutically-relevant macrocyle-based Grb2 SH2 domain-binding antagonists. Additionally, the synthetic approaches used in this study may find application to peptide mimetics directed at other biological targets.

\section{Experimental Section}

\section{Biosensor Analysis}

As indicated in Table 1, Grb2 SH2 domain-binding experiments were performed either on Biacore S51 or Biacore T100 instruments (Biacore Inc., Piscataway NJ). Procedures for analysis on the S51 have been reported. ${ }^{14}$ All biotinylated Grb2 SH2 domain proetins were expressed and purified (Protein Expression Laboratory and The Protein Chemistry Laboratory, SAIC - Frederick). For the T100 using biotin-capture surfaces, neutravidin (Pierce catalogue 
number 31000) dissolved in $10 \mathrm{mM}$ sodium acetate, $\mathrm{pH} 4.5$ was immobilized onto carboxymethyl 5' dextran surface (CM5 sensor chip, Biacore Inc.) by amine coupling using the immobilization wizard supplied by the Biacore T100 software with a $5000 \mathrm{RU}$ target on each of four flow cells. Lyophilized biotinylated Grb2 $\mathrm{SH} 2$ domain protein was reconstituted in $50 \%$ DMSO in $\mathrm{H}_{2} \mathrm{O}$ to make a stock solution of $1 \mathrm{mg} / \mathrm{mL}$ and stored at $-80{ }^{\circ} \mathrm{C}$. A $20 \mu \mathrm{g}$ aliquot of this solution was used for immobilization by diluting in 1XPBS (phosphate buffered Saline, $\mathrm{pH}$ 7.4), which was also used as the running buffer for Grb2 SH2 domain capture. A manual method for building a capture surface was used with a flow rate of $20 \mu \mathrm{L} / \mathrm{min}$ and a capture target of 2500 RU's for flow cells 2 and 4 . Synthetic inhibitors were serially diluted in running buffer to concentrations ranging from $1.25 \mathrm{nM}-1500 \mathrm{nM}$ and serially injected at 25 ${ }^{\circ} \mathrm{C}$ at a flow rate of $30 \mu \mathrm{L} / \mathrm{min}$ for 2 minutes. Each concentration was followed by two blank buffer injections and every injection was performed in duplicate within each experiment. In order to subtract any background noise from each data set, all samples were also run over neutravidin reference surfaces to allow "double referencing." Data were fit to a simple 1:1 interaction model, using the global data analysis program CLAMP. ${ }^{23}$

\section{Synthetic}

$(\beta S, 4 S) \beta-[(1 S)-1-[4-[[B i s($ tert-butyl)phosphinyl]methyl]phenyl]-3-butenyl]-y,2-dioxo-4phenyl-3-oxazolidinebutanoic Acid tert-Butyl Ester (11)

To a solution of $\mathbf{1 0}^{11}(2.00 \mathrm{~g}, 3.70 \mathrm{mmol})$ in THF $(50 \mathrm{~mL})$ at $-78^{\circ} \mathrm{C}$, was added NaHMDS (1.0 M in THF, $4.50 \mathrm{~mL}, 4.50 \mathrm{mmol}$ ) and the mixture was stirred ( 30 minutes) then tert-butyl bromoacetate $(0.82 \mathrm{~mL}, 5.55 \mathrm{mmol})$ was added. The reaction mixture was slowly warmed to room temperature and stirred (overnight). The reaction was quenched by the addition of saturated aqueous $\mathrm{NH}_{4} \mathrm{Cl}$, exacted with EtOAc $(150 \mathrm{~mL})$, dried $\left(\mathrm{Na}_{2} \mathrm{SO}_{4}\right)$ and purified by silica gel column chromatography (hexane : EtOAc) to yield $\mathbf{1 1}$ as a white waxy solid $(2.30 \mathrm{~g}, 95 \%$ yield). ${ }^{1} \mathrm{H}$ NMR $\left(400 \mathrm{MHz}, \mathrm{CDCl}_{3}\right) \delta 7.30-7.15(\mathrm{~m}, 9 \mathrm{H}), 5.48(\mathrm{~m}, 1 \mathrm{H}), 4.95(\mathrm{dd}, J=17.2$, $2.0 \mathrm{~Hz}, 1 \mathrm{H}), 4.86-4.81(\mathrm{~m}, 2 \mathrm{H}), 4.62(\mathrm{~m}, 1 \mathrm{H}), 4.08(\mathrm{t}, J=8.4 \mathrm{~Hz}, 1 \mathrm{H}), 3.95(\mathrm{dd}, J=9.0$, $2.6 \mathrm{~Hz}, 1 \mathrm{H}), 3.02(\mathrm{~d}, J=21.6 \mathrm{~Hz}, 2 \mathrm{H}), 2.88-2.77(\mathrm{~m}, 2 \mathrm{H}), 2.60(\mathrm{dd}, J=16.8,3.6 \mathrm{~Hz}, 1 \mathrm{H})$, $2.52(\mathrm{t}, J=6.8 \mathrm{~Hz}, 2 \mathrm{H}), 1.45(\mathrm{~s}, 18 \mathrm{H}), 1.28(\mathrm{~s}, 9 \mathrm{H}) .{ }^{13} \mathrm{C} \mathrm{NMR}\left(100 \mathrm{MHz}, \mathrm{CDCl}_{3}\right) 174.35$, $170.80,152.98,138.98,138.80,138.76,135.69,132.09,131.99,129.69,129.63,128.62$, $128.31,128.28,127.92,125.50,116.50,82.13,82.05,81.96,69.71,57.66,47.87,44.48,38.31$, $36.89,35.74,35.41,30.31,30.28,30.24,27.81$. ESI-MS (+VE) $m / z: 678.8(\mathrm{M}+\mathrm{Na})^{+}$. HRESI/APCI cacld for $\mathrm{C}_{36} \mathrm{H}_{50} \mathrm{NNaO}_{8} \mathrm{P}(\mathrm{M}+\mathrm{Na})^{+}:$678.3171, Found: 678.3161 .

\section{(2S) [(1S)-1-[4-[[Bis(tert-butyl)phosphinyl]methyl]phenyl]-3-butenyl]-butanedioic Acid Mono (tert-butyl) Ester (7)}

To a solution of compound $11(1.50 \mathrm{~g}, 2.29 \mathrm{mmol})$ in a solution of THF $(15 \mathrm{~mL})$ and $\mathrm{H}_{2} \mathrm{O}(5$ $\mathrm{mL})$ at $0{ }^{\circ} \mathrm{C}$ was added $\mathrm{H}_{2} \mathrm{O}_{2}\left(50 \%\right.$ in $\left.\mathrm{H}_{2} \mathrm{O}, 0.70 \mathrm{~mL}, 12.4 \mathrm{mmol}\right)$ dropwise, followed by $\mathrm{LiOH} \cdot \mathrm{H}_{2} \mathrm{O}(192 \mathrm{mg}, 4.58 \mathrm{mmol})$. The mixture was stirred at $0{ }^{\circ} \mathrm{C}(2 \mathrm{~h})$, then at room temperature $(2 \mathrm{~h})$ and then excess $\mathrm{H}_{2} \mathrm{O}_{2}$ was quenched by addition of saturated aqueous $\mathrm{Na}_{2} \mathrm{SO}_{3}$, THF was removed by rotary evaporation and the residue was acidified to $\mathrm{pH} 3-4$ and exacted with EtOAc $(2 \times 100 \mathrm{~mL})$. The combined organic layer was washed $\left(\mathrm{H}_{2} \mathrm{O}\right)$, dried $\left(\mathrm{Na}_{2} \mathrm{SO}_{4}\right)$ and purified by silica gel column chromatography $\left(\mathrm{CH}_{2} \mathrm{Cl}_{2}: \mathrm{MeOH}\right)$ to yield 7 as a white waxy solid $\left(1.00 \mathrm{~g}, 86 \%\right.$ yield). ${ }^{1} \mathrm{H}$ NMR $\left(400 \mathrm{MHz}, \mathrm{CDCl}_{3}\right) \delta 7.15-7.06(\mathrm{~m}, 4 \mathrm{H})$, $5.56(\mathrm{~m}, 1 \mathrm{H}), 4.93(\mathrm{dd}, J=17.2,1.6 \mathrm{~Hz}, 1 \mathrm{H}), 4.83(\mathrm{dd}, J=10.4,2.0 \mathrm{~Hz}, 1 \mathrm{H}), 3.08(\mathrm{~m}, 1 \mathrm{H})$, $3.03-2.91$ (m, $3 \mathrm{H}), 2.56-2.49$ (m, $3 \mathrm{H}), 2.22$ (dd, $J=16.8,4.4 \mathrm{~Hz}, 1 \mathrm{H}), 1.35$ (m, 27 H). ${ }^{13} \mathrm{C}$ NMR (100 MHz, $\left.\mathrm{CDCl}_{3}\right)$ 176.54, 171.27, 138.97, 136.20, 131.64, 129.88, 129.12, 128.30, 125.97, 116.52, 82.59, 82.52, 80.51, 46.60, 37.80, 36.38, 35.74, 34.66, 30.18, 27.94. ESI-MS (+VE) $\mathrm{m} / z: 533.8(\mathrm{M}+\mathrm{Na})^{+}$. HR-ESI/APCI cacld for $\mathrm{C}_{27} \mathrm{H}_{43} \mathrm{NaO}_{7} \mathrm{P}(\mathrm{M}+\mathrm{Na})^{+}$: 533.2644, Found: 533.2655. 
$(\beta R)$-4-[[Bis(tert-butyloxy)phosphinyl]methyl]- $\beta$-2-propenyl-benzenepropanoic Acid (13)

To a solution of $\mathbf{1 2}$ (prepared as described for its enantiomer using commercially-available (Aldrich) (R)-4-phenyl-2-oxazolidinone $)^{11}(0.420 \mathrm{~g}, 0.78 \mathrm{mmol})$ in a mixture solution of THF (6.0 mL) and $\mathrm{H}_{2} \mathrm{O}(2.0 \mathrm{~mL})$ at $0{ }^{\circ} \mathrm{C}$ was added dropwise $\mathrm{H}_{2} \mathrm{O}_{2}\left(50 \%\right.$ in $\mathrm{H}_{2} \mathrm{O}, 0.23 \mathrm{~mL}, 4.07$ $\mathrm{mmol}$ ) followed by $\mathrm{LiOH} \cdot \mathrm{H}_{2} \mathrm{O}(64 \mathrm{mg}, 1.52 \mathrm{mmol})$. The mixture was stirred at $0{ }^{\circ} \mathrm{C}(2 \mathrm{~h})$ then at $\mathrm{rt}(2 \mathrm{~h})$ and then excess $\mathrm{H}_{2} \mathrm{O}_{2}$ was quenched by addition of saturated aqueous $\mathrm{Na}_{2} \mathrm{SO}_{3}$, THF was removed by rotary evaporation and the residue was acidified to $\mathrm{pH} 3-4$ and exacted with EtOAc $(2 \times 50 \mathrm{~mL})$. The combined organic layer was washed $\left(\mathrm{H}_{2} \mathrm{O}\right)$, dried $\left(\mathrm{Na}_{2} \mathrm{SO}_{4}\right)$ and purified by silica gel column $\left(\mathrm{CH}_{2} \mathrm{Cl}_{2}: \mathrm{MeOH}\right)$ to yield $\mathbf{1 3}$ as a white waxy solid $(250 \mathrm{mg}$, $81 \%$ yield). ${ }^{1} \mathrm{H}$ NMR (400 MHz, $\left.\mathrm{CDCl}_{3}\right) \delta 10.0$ (brs, $\left.1 \mathrm{H}\right), 7.25-7.10(\mathrm{~m}, 4 \mathrm{H}), 5.58(\mathrm{~m}, 1$ H), $4.92-4.85(\mathrm{~m}, 2 \mathrm{H}), 3.15(\mathrm{~m}, 1 \mathrm{H}), 2.88(\mathrm{~d}, J=21.6 \mathrm{~Hz}, 2 \mathrm{H}), 2.63(\mathrm{dd}, J=15.2,6.8 \mathrm{~Hz}$, $1 \mathrm{H}), 2.50(\mathrm{dd}, J=15.6,8.4 \mathrm{~Hz}, 1 \mathrm{H}), 2.40-2.25(\mathrm{~m}, 2 \mathrm{H}), 1.35$ (s, $18 \mathrm{H}) .{ }^{13} \mathrm{C}$ NMR $(100$ $\left.\mathrm{MHz}, \mathrm{CDCl}_{3}\right) \delta 176.09,141.77,135.88,131.16,131.06,129.89,129.82,127.28,116.72,82.66$, 41.25, 40.66, 37.74, 36.32, 30.19. ESI-MS (+VE) $\mathrm{m} / z: 419.0(\mathrm{M}+\mathrm{Na})^{+}$. HR-ESI/APCI cacld for $\mathrm{C}_{21} \mathrm{H}_{33} \mathrm{NaO}_{5} \mathrm{P}(\mathrm{M}+\mathrm{Na})^{+}:$: 419.1963, Found: 419.1969 .

\section{[[4-[(1R)-[2-[2-Oxo-2-[(4S)-2-oxo-4-phenyl-3-oxazolidinyl]ethyl]-3-butenyl]phenyl]methyl]- phosphonic Acid Bis(tert-butyl) Ester (14)}

To a solution of $\mathbf{1 3}(1.15 \mathrm{~g}, 2.90 \mathrm{mmol})$ in THF $(40 \mathrm{~mL})$ at $-78^{\circ} \mathrm{C}$, was added triethylamine $(0.49 \mathrm{~mL}, 3.48 \mathrm{mmol})$ followed by trimethylacetic chloride $(0.39 \mathrm{~mL}, 3.19 \mathrm{mmol})$ dropwise. The mixture was warmed to $0{ }^{\circ} \mathrm{C}$ over 20 minutes, then cooled to $-78{ }^{\circ} \mathrm{C}$ again. Separately, to a solution of (S)-(+)-phenyl-2-oxazolidione (Aldrich) $(568 \mathrm{mg}, 3.48 \mathrm{mmol})$ in THF (40 mL) at $-78^{\circ} \mathrm{C}$ was carefully added $n$-BuLi $(1.60 \mathrm{M}$ in THF, $2.20 \mathrm{~mL}, 3.48 \mathrm{mmol})$ and the mixture was stirred (30 minutes) then transferred to anhydride solution. The final reaction mixture was warmed to room temperature and stirred (overnight). The mixture was diluted with EtOAc $(200 \mathrm{~mL})$, washed $\left(\mathrm{H}_{2} \mathrm{O}\right.$ and brine), dried $\left(\mathrm{Na}_{2} \mathrm{SO}_{4}\right)$, and purified by silica gel column chromatography (hexane : EtOAc) to yield $\mathbf{1 4}$ as a white solid (1.45 g, 95\% yield). ${ }^{1} \mathrm{H}$ NMR $\left(400 \mathrm{MHz}, \mathrm{CDCl}_{3}\right) \delta 7.23-7.21(\mathrm{~m}, 3 \mathrm{H}), 7.11(\mathrm{dd}, J=8.0,2.0 \mathrm{~Hz}, 2 \mathrm{H}), 7.03(\mathrm{~d}, J=8.0 \mathrm{~Hz}$, $2 \mathrm{H}), 7.01-6.99(\mathrm{~m}, 2 \mathrm{H}), 5.55(\mathrm{~m}, 1 \mathrm{H}), 5.30(\mathrm{dd}, J=8.6,3.8 \mathrm{~Hz}, 1 \mathrm{H}), 4.89-4.83(\mathrm{~m}, 2 \mathrm{H})$, $4.57(\mathrm{t}, J=8.8 \mathrm{~Hz}, 1 \mathrm{H}), 4.11(\mathrm{dd}, J=9.0,3.8 \mathrm{~Hz}, 1 \mathrm{H}), 3.36(\mathrm{dd}, J=14.6,6.2 \mathrm{~Hz}, 1 \mathrm{H}), 3.25$ $-3.10(\mathrm{~m}, 2 \mathrm{H}), 2.95$ (d, $J=21.6 \mathrm{~Hz}, 2 \mathrm{H}), 2.29(\mathrm{t}, J=6.8 \mathrm{~Hz}, 2 \mathrm{H}), 1.35(\mathrm{~s}, 18 \mathrm{H}) .{ }^{13} \mathrm{C}$ NMR $\left(100 \mathrm{MHz}, \mathrm{CDCl}_{3}\right) \delta 171.43,153.58,141.37,138.74,135.95,131.51,131.41,129.90,129.84$, $129.03,128.38,127.40,125.53,116.61,82.06,81.97,69.80,57.52,41.02,40.86,40.57,38.19$, 36.77,30.25. ESI-MS (+VE) $m / z: 564.0(\mathrm{M}+\mathrm{Na})^{+}$. HR-ESI/APCI cacld for $\mathrm{C}_{30} \mathrm{H}_{40} \mathrm{NNaO}_{6} \mathrm{P}$ $(\mathrm{M}+\mathrm{Na})^{+}:$564.2490, Found: 564.2495.

\section{( $\beta S, 4 S) \beta-[(1 R)-1-[4-[[B i s($ tert-butyl)phosphinyl]methyl]phenyl]-3-butenyl]-ץ,2-dioxo-4- phenyl-3-oxazolidinebutanoic Acid tert-Butyl Ester (15)}

Treatment of $\mathbf{1 4}$ as described above for the preparation of $\mathbf{1 1}$ provided $\mathbf{1 5}$ as a white waxy solid in $80 \%$ yield. ${ }^{1} \mathrm{H}$ NMR $\left(400 \mathrm{MHz}, \mathrm{CDCl}_{3}\right) \delta 7.34-7.31(\mathrm{~m}, 2 \mathrm{H}), 7.28-7.21(\mathrm{~m}, 3 \mathrm{H}), 7.18$ (dd, $J=8.0,2.4 \mathrm{~Hz}, 2 \mathrm{H}), 7.06(\mathrm{~d}, J=8.0 \mathrm{~Hz}, 2 \mathrm{H}), 5.45-5.35(\mathrm{~m}, 2 \mathrm{H}), 4.82(\mathrm{dd}, J=17.0$, $1.4 \mathrm{~Hz}, 1 \mathrm{H}), 4.75(\mathrm{dd}, J=10.2,1.8 \mathrm{~Hz}, 1 \mathrm{H}), 4.69(\mathrm{~m}, 1 \mathrm{H}), 4.62(\mathrm{t}, J=8.8 \mathrm{~Hz}, 1 \mathrm{H}), 4.17(\mathrm{q}$, $J=8.4 \mathrm{~Hz}, 1 \mathrm{H}), 2.96(\mathrm{~d}, J=21.2 \mathrm{~Hz}, 2 \mathrm{H}), 2.71(\mathrm{td}, J=10.4,3.6 \mathrm{~Hz}, 1 \mathrm{H}), 2.48(\mathrm{dd}, J=21.4$, $11.8 \mathrm{~Hz}, 1 \mathrm{H}), 2.46(\mathrm{~m}, 1 \mathrm{H}), 2.35(\mathrm{~m}, 1 \mathrm{H}), 2.01(\mathrm{~m}, 1 \mathrm{H}), 1.34(\mathrm{~s}, 9 \mathrm{H}), 1.33(\mathrm{~s}, 9 \mathrm{H}), 1.16(\mathrm{~s}$, $9 \mathrm{H}) .{ }^{13} \mathrm{C}$ NMR $\left(100 \mathrm{MHz}, \mathrm{CDCl}_{3}\right) \delta 175.29,170.78,153.62,139.43,139.39,138.80,136.12$, $132.15,132.05,130.16,130.10,128.79,128.13,125.93,116.20,82.01,81.91,80.33,69.69$, $58.19,48.51,43.54,38.19,37.74,37.21,36.77,30.24,30.21,27.86$. ESI-MS (+VE) $\mathrm{m} / z: 678.0$ $(\mathrm{M}+\mathrm{Na})^{+}$. HR-ESI/APCI cacld for $\mathrm{C}_{36} \mathrm{H}_{50} \mathrm{NNaO}_{8} \mathrm{P}(\mathrm{M}+\mathrm{Na})^{+}:$678.3171, Found: 678.3181. 
(2S) [(1R)-1-[4-[[Bis(tert-butyl)phosphinyl]methyl]phenyl]-3-butenyl]-butanedioic Acid Mono (tert-butyl) Ester (8)

Treatment of $\mathbf{1 5}$ as described above for the preparation of $\mathbf{7}$ provided $\mathbf{8}$ as a white waxy solid in $64 \%$ yield. ${ }^{1} \mathrm{H}$ NMR $\left(400 \mathrm{MHz}, \mathrm{CDCl}_{3}\right) \delta 16(\mathrm{dd}, J=8.2,2.6 \mathrm{~Hz}, 2 \mathrm{H}), 7.00(\mathrm{~d}, J=8.0 \mathrm{~Hz}$, $2 \mathrm{H}), 5.44(\mathrm{~m}, 1 \mathrm{H}), 4.84(\mathrm{~d}, J=17.2 \mathrm{~Hz}, 1 \mathrm{H}), 4.76(\mathrm{~d}, J=10.4 \mathrm{~Hz}, 1 \mathrm{H}), 3.00(\mathrm{~d}, J=21.6$ $\mathrm{Hz}, 2 \mathrm{H}), 2.94(\mathrm{~m}, 1 \mathrm{H}), 2.86(\mathrm{~m}, 1 \mathrm{H}), 2.48(\mathrm{~m}, 1 \mathrm{H}), 2.41(\mathrm{~m}, 1 \mathrm{H}), 2.36(\mathrm{dd}, J=16.4,11.2$ $\mathrm{Hz}, 1 \mathrm{H}), 2.02(\mathrm{dd}, J=16.6,3.0 \mathrm{~Hz}, 1 \mathrm{H}), 1.33(\mathrm{~s}, 9 \mathrm{H}), 1.32(\mathrm{~s}, 9 \mathrm{H}), 1.30(\mathrm{~s}, 9 \mathrm{H}) .{ }^{13} \mathrm{C}$ NMR $\left(100 \mathrm{MHz}, \mathrm{CDCl}_{3}\right) \delta 139.11,135.82,131.77,131.67,130.10,130.05,128.09,116.49,82.55$, 82.46, 80.55, 47.26, 47.10, 38.17, 37.91, 36.48, 35.97, 30.21, 30.18, 27.90. ESI-MS (+VE) $\mathrm{m} /$ $z: 533.8(\mathrm{M}+\mathrm{Na})^{+}$. HR-ESI/APCI cacld for $\mathrm{C}_{27} \mathrm{H}_{43} \mathrm{NaO}_{7} \mathrm{P}(\mathrm{M}+\mathrm{Na})^{+}: 533.2644$, Found: 533.2635 .

\section{[4-[(3-Propenyl)amino]phenyl]methyl]-phoshonic Acid Bis(tert-butyl) Ester (17)}

To THF (30 mL) degassed under argon (5 minutes) was added [(4-bromophenyl)methyl]phosphonic acid bis(tert-butyl) ester 16) ${ }^{11}(3.64 \mathrm{~g}, 10.0 \mathrm{mmol})$, allylamine $(1.50 \mathrm{~mL}, 20.0$ mmol), 1,1-bis(diphenylphosphino)ferrocene (dppf) $(620 \mathrm{mg}, 1.0 \mathrm{mmol}), \mathrm{Pd}(\mathrm{dppf})$

$\mathrm{Cl}_{2} \cdot \mathrm{CH}_{2} \mathrm{Cl}_{2}(400 \mathrm{mg}, 0.50 \mathrm{mmol})$ and $\mathrm{NaO}^{t} \mathrm{Bu}(2.00 \mathrm{~g}, 20.0 \mathrm{mmol})$ and the mixture was stirred at reflux (overnight). The mixture was poured into $\mathrm{H}_{2} \mathrm{O}(100 \mathrm{~mL})$, extracted with EtOAc $(3 \times$ $50 \mathrm{~mL}$ ), the combined organic layer was washed (brine), dried $\left(\mathrm{Na}_{2} \mathrm{SO}_{4}\right)$ and purified by silica gel column chromatography (hexane: EtOAc) to yield $\mathbf{1 7}$ as colorless crystals $(2.10 \mathrm{~g}, 62 \%$ yield). ${ }^{1} \mathrm{H}$ NMR (400 MHz, $\left.\mathrm{CDCl}_{3}\right) \delta 7.08(\mathrm{~d}, J=8.4,2.4 \mathrm{~Hz}, 2 \mathrm{H}), 6.57(\mathrm{~d}, J=8.4 \mathrm{~Hz}, 2 \mathrm{H})$, $5.95(\mathrm{~m}, 1 \mathrm{H}), 5.29(\mathrm{dd}, J=17.2,1.6 \mathrm{~Hz}, 1 \mathrm{H}), 5.15(\mathrm{dd}, J=17.8,1.4 \mathrm{~Hz}, 1 \mathrm{H}), 3.78$ (brs, 1 $\mathrm{H}), 3.76(\mathrm{~d}, J=5.6 \mathrm{~Hz}, 2 \mathrm{H}), 2.93(\mathrm{~d}, J=20.8 \mathrm{~Hz}, 2 \mathrm{H}), 1.42(\mathrm{~s}, 18 \mathrm{H}) .{ }^{13} \mathrm{C}$ NMR $(100 \mathrm{MHz}$, $\left.\mathrm{CDCl}_{3}\right) \delta 146.53,135.43,130.57,130.51,122.04,121.94,116.07,112.90,112.87,81.71$, 81.62, 46.67, 37.55, 36.12, 30.31, 30.28. FAB-MS (+VE) $m / z: 339 \mathrm{M}^{+}$. HR-FABMS cacld for $\mathrm{C}_{18} \mathrm{H}_{30} \mathrm{NO}_{3} \mathrm{P}\left(\mathrm{M}^{+}\right): 339.1963$, Found: 339.1961.

\section{[[[[[[2-Oxo-2-[(4S)-2-oxo-4-phenyl-3-oxazolidinyl]ethyl]3-propenyl]amino]phenyl]methyl]- phosphonic Acid Bis(tert-butyl) Ester (19)}

A solution of $\mathbf{1 7}$ (1.50 g, $4.43 \mathrm{mmol}),(4 \mathrm{~S})$-3-(bromoacetyl)-4-phenyl-2-oxazolidinone (18) $19(1.32 \mathrm{~g}, 4.64 \mathrm{mmol})$ and $\operatorname{NEt}(i-\operatorname{Pr})_{2}(1.20 \mathrm{~mL}, 6.65 \mathrm{mmol})$ in DMF $(20 \mathrm{~mL})$ was heated at $60^{\circ} \mathrm{C}$ (overnight). The reaction mixture was diluted by the addition of EtOAc $(100 \mathrm{~mL})$, washed $\left(\mathrm{H}_{2} \mathrm{O}\right.$ and brine), dried $\left(\mathrm{Na}_{2} \mathrm{SO}_{4}\right)$ and purified by silica gel column chromatography (hexane: EtOAc) to yield 19 as a white waxy solid $\left(2.20 \mathrm{~g}, 92 \%\right.$ yield). ${ }^{1} \mathrm{H}$ NMR $\left(400 \mathrm{MHz}, \mathrm{CDCl}_{3}\right) \delta$ $7.29-7.27$ (m, $5 \mathrm{H}), 7.00$ (dd, $J=8.8,2.4 \mathrm{~Hz}, 2 \mathrm{H}), 6.45$ (d, $J=8.4 \mathrm{~Hz}, 2 \mathrm{H}), 5.80(\mathrm{~m}, 1 \mathrm{H})$, $5.42(\mathrm{dd}, J=8.8,4.0 \mathrm{~Hz}, 1 \mathrm{H}), 5.13(\mathrm{dd}, J=17.2,1.6 \mathrm{~Hz}, 1 \mathrm{H}), 5.10(\mathrm{dd}, J=11.2,1.6 \mathrm{~Hz}, 1$ H), $4.75(\mathrm{~d}, J=17.6 \mathrm{~Hz}, 1 \mathrm{H}), 4.72(\mathrm{~d}, J=20.4 \mathrm{~Hz}, 1 \mathrm{H}), 4.58(\mathrm{~d}, J=19.2 \mathrm{~Hz}, 1 \mathrm{H}), 4.33$ (dd, $J=9.0,3.8 \mathrm{~Hz}, 1 \mathrm{H}), 3.93(\mathrm{dd}, J=16.8,5.2 \mathrm{~Hz}, 1 \mathrm{H}), 3.84(\mathrm{dd}, J=16.8,5.2 \mathrm{~Hz}, 1 \mathrm{H}), 2.89$ $(\mathrm{d}, J=20.8 \mathrm{~Hz}, 2 \mathrm{H}), 1.40$ (s, $18 \mathrm{H}) .{ }^{13} \mathrm{C}$ NMR $\left(100 \mathrm{MHz}, \mathrm{CDCl}_{3}\right) \delta 170.03,154.04,146.73$, $138.63,133.98,130.40,130.33,129.13,128.77,125.91,121.82,121.72,116.51,112.36,81.79$, 81.74, 81.70, 81.65, 70.78, 57.43, 54.14, 54.05, 37.39, 35.95, 30.31, 30.28. FAB-MS (+VE) $m / z: 542 \mathrm{M}^{+}$. HR-FAB cacld for $\mathrm{C}_{29} \mathrm{H}_{39} \mathrm{~N}_{2} \mathrm{O}_{6} \mathrm{P}\left(\mathrm{M}^{+}\right)$: 542.2546, Found: 542.2535 .

\section{$(\beta R, 4 S) \beta-[[[4-[[B i s($ tert-butyl)phosphinyl]methyl]phenyl]3-propenyl]amino]-ү,2-dioxo-4- phenyl-3-oxazolidinebutanoic Acid tert-Butyl Ester (20)}

Treatment of $\mathbf{1 9}$ as described above for the preparation of $\mathbf{1 1}$ provided $\mathbf{2 0}$ as a pale yellow waxy solid in $59 \%$ yield. ${ }^{1} \mathrm{H}$ NMR $\left(400 \mathrm{MHz}, \mathrm{CDCl}_{3}\right) \delta 7.34-7.22(\mathrm{~m}, 5 \mathrm{H}), 7.07$ (dd, $J=8.8,2.4$ $\mathrm{Hz}, 2 \mathrm{H}), 6.75(\mathrm{dd}, J=8.4 \mathrm{~Hz}, 2 \mathrm{H}), 6.14(\mathrm{dd}, J=9.2,5.6 \mathrm{~Hz}, 1 \mathrm{H}), 5.76(\mathrm{~m}, 1 \mathrm{H}), 5.22(\mathrm{dd}$, $J=8.4,2.8 \mathrm{~Hz}, 1 \mathrm{H}), 5.10(\mathrm{dd}, J=17.0,1.4 \mathrm{~Hz}, 1 \mathrm{H}), 5.03(\mathrm{dd}, J=10.4,1.4 \mathrm{~Hz}, 1 \mathrm{H}), 4.51(\mathrm{t}$, $J=8.6 \mathrm{~Hz}, 1 \mathrm{H}), 4.18(\mathrm{ddd}, J=8.8,2.8,1.2 \mathrm{~Hz}, 1 \mathrm{H}), 3.87(\mathrm{dd}, J=18.2,4.6 \mathrm{~Hz}, 1 \mathrm{H}), 3.77$ $(\mathrm{dd}, J=18.0,2.0 \mathrm{~Hz}, 1 \mathrm{H}), 2.90(\mathrm{~d}, J=20.4 \mathrm{~Hz}, 2 \mathrm{H}), 2.86(\mathrm{dd}, J=16.2,9.2 \mathrm{~Hz}, 1 \mathrm{H}), 2.49$ 
(dd, $J=16.2,5.6 \mathrm{~Hz}, 1 \mathrm{H}), 1.38(\mathrm{~s}, 18 \mathrm{H}), 1.23(\mathrm{~s}, 9 \mathrm{H}) .{ }^{13} \mathrm{C} \mathrm{NMR}\left(100 \mathrm{MHz}, \mathrm{CDCl}_{3}\right)$ 170.91, $169.64,152.74,146.11,146.08,138.68,135.38,130.39,130.32,128.95,128.42,125.69$, $122.84,122.74,115.10,114.15,81.83,81.77,81.74,81.68,80.92,70.06,67.81,57.78,56.13$, 49.26, 37.45, 36.02, 33.64, 30.24, 27.74, 25.51. FABMS (+VE) $m / z: 656 \mathrm{M}^{+}$. HR-FABMS cacld for $\mathrm{C}_{35} \mathrm{H}_{49} \mathrm{~N}_{2} \mathrm{O}_{8} \mathrm{P}\left(\mathrm{M}^{+}\right)$: 656.3227, Found: 656.3216 .

\section{( $\beta R$ ) $\beta$-[[[4-[[Bis(tert-butyl)phosphinyl]methyl]phenyl]3-propenyl]amino]-butandioic Acid Mono(tert-butyl) Ester (9)}

Treatment of $\mathbf{2 0}$ as described above for the preparation of $\mathbf{7}$ provided $\mathbf{9}$ as a pale yellow waxy solid in $59 \%$ yield. ${ }^{1} \mathrm{H} \mathrm{NMR}\left(400 \mathrm{MHz}, \mathrm{CDCl}_{3}\right) 7.05(\mathrm{dd}, J=8.8,2.0 \mathrm{~Hz}, 2 \mathrm{H}), 6.74(\mathrm{~d}, J=$ $8.4 \mathrm{~Hz}, 2 \mathrm{H}), 5.84(\mathrm{~m}, 1 \mathrm{H}), 5.20(\mathrm{~d}, J=17.2,1 \mathrm{H}), 5.11(\mathrm{~d}, J=10.4,1 \mathrm{H}), 4.83(\mathrm{t}, J=7.0 \mathrm{~Hz}$, $1 \mathrm{H}), 3.95(\mathrm{dd}, J=17.6,4.8 \mathrm{~Hz}, 1 \mathrm{H}), 3.88(\mathrm{dd}, J=17.4,4.2 \mathrm{~Hz}, 1 \mathrm{H}), 3.01(\mathrm{dd}, J=16.4,6.4$ $\mathrm{Hz}, 1 \mathrm{H}), 2.93(\mathrm{~d}, J=21.2 \mathrm{~Hz}, 2 \mathrm{H}), 2.66(\mathrm{dd}, J=16.2,7.8 \mathrm{~Hz}, 1 \mathrm{H}), 1.40(\mathrm{~s}, 9 \mathrm{H}), 1.39$ (s, 9 $\mathrm{H}), 1.38(\mathrm{~s}, 9 \mathrm{H}) .{ }^{13} \mathrm{C} \mathrm{NMR}\left(100 \mathrm{MHz}, \mathrm{CDCl}_{3}\right) \delta 174.15,170.42,146.90,146.86,135.44$, $130.37,122.15,122.05,116.26,114.85,82.70,82.60,80.93,59.35,51.73,37.10,36.42,35.66$, $30.24,30.21,27.94$. FAB-MS (+VE) $m / z: 512(\mathrm{M}+\mathrm{H})^{+}$. HR-FAB cacld for $\mathrm{C}_{26} \mathrm{H}_{43} \mathrm{NO}_{7} \mathrm{P}(\mathrm{M}$ $+\mathrm{H})^{+}:$512.2777, Found: 512.2775.

1-[[(2S,3S)-3-[4-[[Bis(tert-butyloxy)phosphinyl]methyl]phenyl]-2-[2-(tert-butyloxy)-2oxoethyl]-1-oxo-4-pentenyl]amino]cyclohexanecarbonyl- $L$-asparaginyl-4,5-didehydro- $\mathrm{N}-(1-$ naphthalenylmethyl)-L-homoallylglycinamide (21)

To a solution of $6(160 \mathrm{mg}, 0.321 \mathrm{mmol})$ in DMF $(1.0 \mathrm{~mL})$ was added HOAt $(64 \mathrm{mg}, 0.472$ $\mathrm{mmol})$, EDCI $(121 \mathrm{mg}, 0.63 \mathrm{mmol})$ and $\operatorname{NEt}(i-\operatorname{Pr})_{2}(0.27 \mathrm{~mL}, 1.57 \mathrm{mmol})$ and the mixture was stirred at room temperature ( 15 minutes). To this was added a solution of tripeptide $\mathbf{5}$ ( $80 \mathrm{mg}$, $0.157 \mathrm{mmol})$ in DMF $(1.0 \mathrm{~mL})$, then the mixture was heated $\left(50^{\circ} \mathrm{C}\right)$ and stirred $(36 \mathrm{~h})$. The mixture was coolded to room temperature, diluted with $\mathrm{H}_{2} \mathrm{O}(20 \mathrm{~mL})$, extracted with EtOAc $(3 \times 50 \mathrm{~mL})$, the combined organic phase was washed (brine), dried $\left(\mathrm{Na}_{2} \mathrm{SO}_{4}\right)$ and purified by silica gel column chromatography (dichloromethane: $\mathrm{MeOH}$ ) to afford $\mathbf{2 1}$ as a pale yellow solid (33 mg, 21\% yield). ${ }^{1} \mathrm{H} \mathrm{NMR}\left(\mathrm{CDCl}_{3}\right) \delta 8.00(\mathrm{~m}, 1 \mathrm{H}), 7.80(\mathrm{~m}, 1 \mathrm{H}), 7.70(\mathrm{~m}, 1 \mathrm{H})$, $7.60(\mathrm{~m}, 1 \mathrm{H}), 7.50-7.30$ (m, $5 \mathrm{H}), 7.25-7.00(\mathrm{~m}, 7 \mathrm{H}), 6.34$ (brs, $1 \mathrm{H}), 5.80(\mathrm{~m}, 1 \mathrm{H}), 5.60$ (m, $1 \mathrm{H}), 5.03-4.80(\mathrm{~m}, 6 \mathrm{H}), 4.35(\mathrm{~m}, 1 \mathrm{H}), 4.25(\mathrm{~m}, 1 \mathrm{H}), 3.50(\mathrm{~m}, 1 \mathrm{H}), 3.00-2.85(\mathrm{~m}, 3$ H), $2.70-2.40$ (m, 4 H), $2.20-1.90$ (m, 4 H), $1.50-1.20$ (m, 37 H). FAB-MS (+VE) $m / z(M$ $+\mathrm{H})^{+}: 986.7$.

1-[[(2S,3S)-3-[4-[[Bis(tert-butyloxy)phosphinyl]methyl]phenyl]-2-[2-(tert-butyloxy)-2oxoethyl]-1-oxo-5-hexenyl]amino]cyclohexanecarbonyl-L-asparaginyl-4,5-didehydro- $\mathrm{N}-(1-$ naphthalenylmethyl)-L-norvalinamide (22)

Coupling pTyr mimetic $\mathbf{7}$ with tripeptide $\mathbf{4}$ as described above for the preparation of $\mathbf{2 1}$ provided 22 as a colorless solid in $45 \%$ yield. ${ }^{1} \mathrm{H}$ NMR $\left(400 \mathrm{MHz}, \mathrm{CDCl}_{3}\right) \delta 8.02(\mathrm{~d}, J=8.0 \mathrm{~Hz}, 1 \mathrm{H})$, $7.81(\mathrm{~d}, J=7.6 \mathrm{~Hz}, 1 \mathrm{H}), 7.72(\mathrm{~d}, J=8.0 \mathrm{~Hz}, 2 \mathrm{H}), 7.56-7.36(\mathrm{~m}, 7 \mathrm{H}), 7.20(\mathrm{dd}, J=8.0,1.6$ $\mathrm{Hz}, 2 \mathrm{H}), 7.08(\mathrm{~d}, J=8.0 \mathrm{~Hz}, 2 \mathrm{H}), 6.77(\mathrm{~s}, 1 \mathrm{H}), 6.43(\mathrm{~s}, 1 \mathrm{H}), 5.80(\mathrm{~m}, 1 \mathrm{H}), 5.44(\mathrm{~m}, 1 \mathrm{H})$, $5.14-4.77(\mathrm{~m}, 6 \mathrm{H}), 4.46(\mathrm{~m}, 1 \mathrm{H}), 4.32(\mathrm{q}, J=6.0 \mathrm{~Hz}, 1 \mathrm{H}), 3.00-2.92(\mathrm{~m}, 4 \mathrm{H}), 2.80(\mathrm{~m}$, $1 \mathrm{H}), 2.70-2.55(\mathrm{~m}, 3 \mathrm{H}), 2.50-2.40(\mathrm{~m}, 3 \mathrm{H}), 2.25(\mathrm{~m}, 1 \mathrm{H}), 1.60-1.30(\mathrm{~m}, 34 \mathrm{H}), 1.20$ $(\mathrm{m}, 1 \mathrm{H}), 1.05(\mathrm{~m}, 1 \mathrm{H}), 0.90(\mathrm{~m}, 1 \mathrm{H}) .{ }^{13} \mathrm{C} \mathrm{NMR}\left(100 \mathrm{MHz}, \mathrm{CDCl}_{3}\right) \delta 174.88,173.97,172.94$, $172.63,171.10,139.81,135.40,134.31,133.80,133.62,131.37,130.14,130.07,128.43$, $128.16,127.78,126.07,125.75,125.57,125.35,123.64,117.45,116.83,82.21,82.07,81.57$, 59.56, 53.98, 51.90, 47.09, 45.44, 41.15, 38.03, 36.41, 35.54, 35.29, 34.56, 30.28, 27.97, 24.78, 20.88. ESI-MS (+VE) $m / z: 986.2(\mathrm{M}+\mathrm{H})^{+}$. HR-ESI/APCI cacld for $\mathrm{C}_{54} \mathrm{H}_{77} \mathrm{~N}_{5} \mathrm{O}_{10} \mathrm{P}(\mathrm{M}+$ $\mathrm{H})^{+}:$986.5408, Found: 986.5399 . 
1-[[(2R,3S)-3-[4-[[Bis(tert-butyloxy)phosphinyl]methyl]phenyl]-2-[2-(tert-butyloxy)-2oxoethyl]-1-oxo-5-hexenyl]amino]cyclohexanecarbonyl-L-asparaginyl-4,5-didehydro- $\mathrm{N}$-(1naphthalenylmethyl)-L-norvalinamide (23)

Coupling pTyr mimetic $\mathbf{8}$ with tripeptide $\mathbf{4}$ as described above for the preparation of $\mathbf{2 1}$ provided 23 as a colorless solid in $38 \%$ yield. ${ }^{1} \mathrm{H}$ NMR $\left(400 \mathrm{MHz}, \mathrm{CDCl}_{3}\right) \delta 8.03(\mathrm{~d}, J=8.4 \mathrm{~Hz}, 1 \mathrm{H})$, $7.96(\mathrm{~d}, J=5.6 \mathrm{~Hz}, 1 \mathrm{H}), 7.86(\mathrm{~d}, J=8.4 \mathrm{~Hz}, 1 \mathrm{H}), 7.81(\mathrm{~d}, J=8.0 \mathrm{~Hz}, 1 \mathrm{H}), 7.72(\mathrm{~d}, J=7.6$ $\mathrm{Hz}, 1 \mathrm{H}), 7.51-7.36(\mathrm{~m}, 5 \mathrm{H}), 7.27-7.20(\mathrm{~m}, 4 \mathrm{H}), 6.97$ (d, $J=7.6 \mathrm{~Hz}, 2 \mathrm{H}), 6.58$ (brs, $1 \mathrm{H})$, $5.81(\mathrm{~m}, 1 \mathrm{H}), 5.71(\mathrm{~m}, 1 \mathrm{H}), 5.42-5.34(\mathrm{~m}, 2 \mathrm{H}), 5.18-5.00(\mathrm{~m}, 3 \mathrm{H}), 4.86-4.77(\mathrm{~m}, 2 \mathrm{H})$, $4.47(\mathrm{~m}, 1 \mathrm{H}), 3.00(\mathrm{~d}, J=21.2 \mathrm{~Hz}, 2 \mathrm{H}), 2.89-2.83(\mathrm{~m}, 2 \mathrm{H}), 2.79-2.71(\mathrm{~m}, 2 \mathrm{H}), 2.70-$ $2.62(\mathrm{~m}, 3 \mathrm{H}), 2.52(\mathrm{~m}, 1 \mathrm{H}), 2.37(\mathrm{~m}, 1 \mathrm{H}), 2.19(\mathrm{~m}, 1 \mathrm{H}), 1.95-1.80(\mathrm{~m}, 3 \mathrm{H}), 1.75-1.50$ $(\mathrm{m}, 5 \mathrm{H}), 1.50-1.10(\mathrm{~m}, 29 \mathrm{H}) .{ }^{13} \mathrm{C} \mathrm{NMR}\left(100 \mathrm{MHz}, \mathrm{CDCl}_{3}\right) \delta 175.16,174.91,172.84,171.09$, $170.96,138.94,135.62,134.39,133.79,133.63,133.58,131.40,130.29,130.22,128.64$, $128.40,128.08,127.73,126.82,126.71,126.04,125.71,125.54,125.34,123.66,117.48$, $116.65,82.06,81.97,81.49,59.24,53.98,52.11,48.23,46.20,41.25,38.66,38.16,36.74$, 36.05, 35.80, 35.38, 30.25, 27.91, 21.29, 21.04, 20.71. ESI-MS (+VE) $m / z: 986.4(\mathrm{M}+\mathrm{H})^{+}$. HR-ESI/APCI cacld for $\mathrm{C}_{54} \mathrm{H}_{76} \mathrm{~N}_{5} \mathrm{NaO}_{10} \mathrm{P}(\mathrm{M}+\mathrm{Na})^{+}$: 1008.5227. Found: 1008.5209 .

\title{
1-[( $\beta R) \beta-[[[4-[[B i s($ tert-butyl)phosphinyl]methyl]phenyl]3-propenyl]amino]- $\gamma-($ tert-butyl) butandioyl]amino]cyclohexanecarbonyl-L-asparaginyl-4,5-didehydro- $\mathrm{N}$-(1- naphthalenylmethyl)-L-norvalinamide (24)
}

\begin{abstract}
Coupling pTyr mimetic 9 with tripeptide $\mathbf{4}$ as described above for the preparation of $\mathbf{2 1}$ provided 24 as a white waxy solid in $65 \%$ yield. ${ }^{1} \mathrm{H}$ NMR $\left(400 \mathrm{MHz}, \mathrm{CDCl}_{3}\right) \delta 8.04(\mathrm{~d}, J=8.0 \mathrm{~Hz}, 1$ H), $7.82(\mathrm{~m}, 2 \mathrm{H}), 7.74(\mathrm{~d}, J=8.0 \mathrm{~Hz}, 1 \mathrm{H}), 7.68(\mathrm{~d}, J=8.4 \mathrm{~Hz}, 1 \mathrm{H}), 7.50-7.36(\mathrm{~m}, 5 \mathrm{H})$, 7.19 (s, $1 \mathrm{H}), 7.17$ (dd, $J=8.8,2.4 \mathrm{~Hz}, 2 \mathrm{H}), 6.87(\mathrm{~s}, 1 \mathrm{H}), 6.74(\mathrm{~d}, J=8.8 \mathrm{~Hz}, 2 \mathrm{H}), 5.90(\mathrm{~m}$, $1 \mathrm{H}), 5.72(\mathrm{~m}, 1 \mathrm{H}), 5.48(\mathrm{~s}, 1 \mathrm{H}), 5.24-5.07(\mathrm{~m}, 4 \mathrm{H}), 5.01(\mathrm{dd}, J=10.0,0.8 \mathrm{~Hz}, 1 \mathrm{H}), 4.75$ -4.69 (m, 2 H), 4.50 (m, $1 \mathrm{H}), 4.41(\mathrm{dd}, J=11.2,5.6 \mathrm{~Hz}, 1 \mathrm{H}), 4.05$ (dd, $J=17.4,4.4 \mathrm{~Hz}, 1$ H), $3.95(\mathrm{dd}, J=17.4,4.4 \mathrm{~Hz}, 1 \mathrm{H}), 2.98-2.80(\mathrm{~m}, 4 \mathrm{H}), 2.76(\mathrm{dd}, J=15.2,6.0 \mathrm{~Hz}, 1 \mathrm{H}), 2.69$ $(\mathrm{dd}, J=17.2,7.2 \mathrm{~Hz}, 1 \mathrm{H}), 2.55(\mathrm{dd}, J=15.2,5.6 \mathrm{~Hz}, 1 \mathrm{H}), 2.50(\mathrm{~m}, 1 \mathrm{H}), 1.60-1.45(\mathrm{~m}, 5$ $\mathrm{H}), 1.42$ (s, $18 \mathrm{H}), 1.38-1.25(\mathrm{~m}, 11 \mathrm{H}), 1.06(\mathrm{~m}, 2 \mathrm{H}), 0.95(\mathrm{~m}, 1 \mathrm{H}) .{ }^{13} \mathrm{C}$ NMR $(100 \mathrm{MHz}$, $\left.\mathrm{CDCl}_{3}\right) \delta 174.72,172.64,170.93,170.79,145.95,134.68,134.43,133.83,133.63,131.52$, $130.85,130.78,128.32127 .75,126.09,126.02,125.52,125.36,123.82,117.37,117.01$, $114.91,82.13,82.03,81.97,81.87,81.41,61.55,59.33,53.71,52.02,50.38,41.28,37.46$, $36.03,35.40,35.12,34.91,34.04,30.30,28.14,27.88,24.64,21.05,20.98$. MALDI-MS (+VE) $\mathrm{m} / z: 1010(\mathrm{M}+\mathrm{Na})^{+}$. HR-MALDI cacld for $\mathrm{C}_{53} \mathrm{H}_{75} \mathrm{~N}_{6} \mathrm{NaO}_{10} \mathrm{P}(\mathrm{M}+\mathrm{Na})^{+}:$1009.5180. Found: 1009.5159 .
\end{abstract}

\section{(9S,10S,11E,15S,18S)-18-(2-Amino-2-oxoethyl)-15-[[(1-naphthalenylmethyl)amino] carbonyl]-8,17,20-trioxo-10-[4-(phosphonomethyl)phenyl]-7,16,19-triazaspiro[5.14]eicos-11- ene-9-acetic Acid (2c)}

A solution of tetrapeptide $21(30 \mathrm{mg}, 0.0304 \mathrm{mmol})$ in anhydrous dichloromethane $(30 \mathrm{~mL})$ was degassed under argon (5 minutes) then Grubbs $2^{\text {nd }}$ generation catalyst $\left[\left(\left(\mathrm{PCy}_{3}\right)(\mathrm{Im}\right.\right.$ $\left.\left.\left.(\mathrm{Mes})_{2}\right) \mathrm{Ru}=\mathrm{CHPh}\right)\right]^{20}(13 \mathrm{mg}, 0.0152 \mathrm{mmol})$ was added and the mixture was refluxed ( 2 days). The mixture was concentrated and purified by silica gel column chromatography (dichoromethane: $\mathrm{MeOH}$ ) to provide intermediated tert-butyl-protected product as a brown material. This was treated with a mixture of $\mathrm{CF}_{3} \mathrm{CO}_{2} \mathrm{H}(3.7 \mathrm{~mL})$, triethylsilane $(0.10 \mathrm{~mL})$ and $\mathrm{H}_{2} \mathrm{O}(0.20 \mathrm{~mL})$ at room temperature $(1 \mathrm{~h})$. The solvent was removed and the residue was purified by reverse phase preparative HPLC on a Phenomenex $\mathrm{C}_{18}$ column $(21 \mathrm{~mm}$ dia $\times 250$ $\mathrm{mm}$; cat. No. 00G-4436-P0) using a linear gradient from solvent $\mathrm{A}, 0 \%$ aqueous acetonitrile $\left(0.1 \% \mathrm{CF}_{3} \mathrm{CO}_{2} \mathrm{H}\right)$ to solvent $\mathrm{B}, 100 \%$ acetonitrile $\left(0.1 \% \mathrm{CF}_{3} \mathrm{CO}_{2} \mathrm{H}\right)$ over 25 minutes at a flow rate of $10.0 \mathrm{~mL} /$ minute (detection at $225 \mathrm{~nm}$ ), retention time: 23.1 minutes. Lyophilization provided the macrocyclic product $2 \mathrm{c}$ as a white powder ( $3 \mathrm{mg}, 12 \%$ yield from $\mathbf{2 1}$ ). ${ }^{1} \mathrm{H}$ NMR 
$\left(\mathrm{DMSO}_{6}\right) \delta 8.56(\mathrm{~s}, 1 \mathrm{H}), 8.33(\mathrm{~d}, J=7.2 \mathrm{~Hz}, 1 \mathrm{H}), 8.10-8.06(\mathrm{~m}, 2 \mathrm{H}), 7.93(\mathrm{~m}, 1 \mathrm{H}), 7.80$ $(\mathrm{d}, J=8.4 \mathrm{~Hz}, 1 \mathrm{H}), 7.60(\mathrm{~m}, 1 \mathrm{H}) 7.55-7.52(\mathrm{~m}, 3 \mathrm{H}), 7.48(\mathrm{~d}, J=6.8 \mathrm{~Hz}, 1 \mathrm{H}), 7.40(\mathrm{~m}, 1$ H), $7.30-7.17(\mathrm{~m}, 5 \mathrm{H}), 7.76-7.74(\mathrm{~m}, 2 \mathrm{H}), 4.83(\mathrm{dd}, J=15.8,5.8 \mathrm{~Hz}, 1 \mathrm{H}), 4.74(\mathrm{dd}, J=$ 15.6, 7.5 Hz, $1 \mathrm{H}), 4.45$ (m, $1 \mathrm{H}), 4.32(\mathrm{dd}, J=12.0,5.0 \mathrm{~Hz}, 1 \mathrm{H}), 4.09$ (m, $1 \mathrm{H}), 3.30(\mathrm{~d}, J=$ $11.6 \mathrm{~Hz}, 1 \mathrm{H}), 2.93(\mathrm{~d}, J=21.2 \mathrm{~Hz}, 1 \mathrm{H}), 2.80(\mathrm{dd}, J=15.4,5.0 \mathrm{~Hz}, 1 \mathrm{H}), 2.67$ (dd, $J=16.2$, $12.2 \mathrm{~Hz}, 1 \mathrm{H}), 2.42(\mathrm{dd}, J=15.6,5.2 \mathrm{~Hz}, 1 \mathrm{H}), 2.30(\mathrm{~m}, 1 \mathrm{H}), 2.00-1.85$ (m, $5 \mathrm{H}), 1.83-1.65$ $(\mathrm{m}, 3 \mathrm{H}), 1.57-1.35(\mathrm{~m}, 5 \mathrm{H}), 1.15(\mathrm{~m}, 1 \mathrm{H})$. FAB-MS (-VE) $m / z(\mathrm{M}-\mathrm{H})^{-}{ }^{-}$788.6. HR-MALDI cacld for $\mathrm{C}_{40} \mathrm{H}_{48} \mathrm{~N}_{5} \mathrm{NaO}_{10} \mathrm{P}(\mathrm{M}+\mathrm{Na})^{+}:$812.3031, Found: 812.3010.

(9S,10R,12E,15S,18S)-18-(2-Amino-2-oxoethyl)-15-[[(1-naphthalenylmethyl)amino] carbonyl]-8,17,20-trioxo-10-[4-(phosphonomethyl)phenyl]-7,16,19-triazaspiro[5.14]eicos-12ene-9-acetic Acid (2d)
Ring-closing metathesis of $\mathbf{2 3}$ followed by deprotection and HPLC purification as reported above for the conversion of $\mathbf{2 1}$ to $\mathbf{2 c}$ (linear gradient solvent B: $0 \%$ - $100 \%$ over 35 minutes; retention time: 26.5 minutes) yielded the macrocyclic final product $\mathbf{2 d}$ as a white powder (6 $\mathrm{mg}, 30 \%$ yield from 23$).{ }^{1} \mathrm{H}$ NMR $\left(400 \mathrm{MHz}\right.$, acetone- $d_{6}$ with one drop $\left.\mathrm{D}_{2} \mathrm{O}\right) \delta 8.06(\mathrm{~d}, J=$ $8.8 \mathrm{~Hz}, 1 \mathrm{H}), 7.92(\mathrm{~s}, 1 \mathrm{H}), 7.85(\mathrm{~d}, J=7.6 \mathrm{~Hz}, 1 \mathrm{H}), 7.75(\mathrm{~d}, J=8.4 \mathrm{~Hz}, 1 \mathrm{H}), 7.54-7.38(\mathrm{~m}$, $4 \mathrm{H}), 7.20(\mathrm{~d}, J=7.6 \mathrm{~Hz}, 2 \mathrm{H}), 7.12(\mathrm{~d}, J=8.0 \mathrm{~Hz}, 2 \mathrm{H}), 5.37$ (dd, $J=17.4,9.4 \mathrm{~Hz}, 1 \mathrm{H}), 5.20$ $(\mathrm{m}, 1 \mathrm{H}), 4.88\left(\mathrm{AB}, J_{A B}=15.6 \mathrm{~Hz}, 1 \mathrm{H}\right), 4.78\left(\mathrm{AB}, J_{A B}=15.6 \mathrm{~Hz}, 1 \mathrm{H}\right), 4.64(\mathrm{~m}, 1 \mathrm{H}), 4.32$ $(\mathrm{m}, 1 \mathrm{H}), 3.11(\mathrm{~m}, 1 \mathrm{H}), 3.03(\mathrm{~d}, J=21.6 \mathrm{~Hz}, 2 \mathrm{H}), 2.96-2.87(\mathrm{~m}, 2 \mathrm{H}), 2.79(\mathrm{dd}, J=15.8$, $6.2 \mathrm{~Hz}, 1 \mathrm{H}), 2.59(\mathrm{dd}, J=15.4,5.0 \mathrm{~Hz}, 1 \mathrm{H}), 2.51(\mathrm{~m}, 1 \mathrm{H}), 2.43(\mathrm{dd}, J=14.0,7.6 \mathrm{~Hz}, 1 \mathrm{H})$, $2.26(\mathrm{dd}, J=16.6,9.8 \mathrm{~Hz}, 2 \mathrm{H}), 2.10(\mathrm{~m}, 1 \mathrm{H}), 1.88-1.77(\mathrm{~m}, 2 \mathrm{H}), 1.59-1.40(\mathrm{~m}, 5 \mathrm{H}), 1.26$ $-1.12(\mathrm{~m}, 3 \mathrm{H})$. ESI-MS (+VE) $\mathrm{m} / z: 812(\mathrm{M}+\mathrm{Na})^{+}$. HR-ESI/APCI cacld for $\mathrm{C}_{40} \mathrm{H}_{48} \mathrm{~N}_{5} \mathrm{NaO}_{10} \mathrm{P}(\mathrm{M}+\mathrm{Na})^{+}:$812.3036, Found: 812.3011.

(9S,10S,12Z,15S,18S)-18-(2-Amino-2-oxoethyl)-15-[[(1-naphthalenylmethyl)amino] carbonyl]-8,17,20-trioxo-10-[4-(phosphonomethyl)phenyl]-7,16,19-triazaspiro[5.14]eicos-12ene-9-acetic Acid (2e)

\begin{abstract}
Ring-closing metathesis of $\mathbf{2 2}$ followed by deprotection and HPLC purification as reported above for the conversion of $\mathbf{2 1}$ to $\mathbf{2 c}$ (linear gradient solvent B: $0 \%$ - $70 \%$ over 30 minutes; retention time: 27.5 minutes) yielded the macrocyclic final product $\mathbf{2 e}$ as a white powder (16 $\mathrm{mg}, 50 \%$ yield from 22). ${ }^{1} \mathrm{H}$ NMR $\left(400 \mathrm{MHz}, \mathrm{DMSO}-d_{6}\right) \delta 8.36(\mathrm{~s}, 1 \mathrm{H}), 8.24(\mathrm{~d}, J=7.2 \mathrm{~Hz}$, $1 \mathrm{H}), 8.07(\mathrm{~d}, J=8.0 \mathrm{~Hz}, 1 \mathrm{H}), 8.03(\mathrm{t}, J=6.0 \mathrm{~Hz}, 1 \mathrm{H}), 7.94(\mathrm{dd}, J=8.0,1.2 \mathrm{~Hz}, 1 \mathrm{H}), 7.83$ $(\mathrm{d}, J=8.0 \mathrm{~Hz}, 1 \mathrm{H}), 7.59-7.43(\mathrm{~m}, 7 \mathrm{H}), 7.22(\mathrm{dd}, J=8.4,2.0 \mathrm{~Hz}, 2 \mathrm{H}), 7.00(\mathrm{~s}, 1 \mathrm{H}), 6.94$ $(\mathrm{d}, J=9.2 \mathrm{~Hz}, 1 \mathrm{H}), 5.21(\mathrm{t}, J=11.6 \mathrm{~Hz}, 1 \mathrm{H}), 5.12(\mathrm{td}, J=10.8,3.2 \mathrm{H}, 1 \mathrm{H}), 4.76(\mathrm{t}, J=6.0$ $\mathrm{Hz}, 2 \mathrm{H}), 4.38-4.30(\mathrm{~m}, 2 \mathrm{H}), 3.33(\mathrm{t}, J=11.6 \mathrm{~Hz}, 1 \mathrm{H}), 3.06(\mathrm{~d}, J=11.6 \mathrm{~Hz}, 1 \mathrm{H}), 2.94(\mathrm{~d}$, $J=21.2 \mathrm{~Hz}, 2 \mathrm{H}), 2.76-2.60(\mathrm{~m}, 3 \mathrm{H}), 2.40(\mathrm{dd}, J=15.6,4.8 \mathrm{~Hz}, 1 \mathrm{H}), 2.23(\mathrm{~m}, 2 \mathrm{H}), 2.14$ (m, $2 \mathrm{H}), 1.76-1.67$ (m, $3 \mathrm{H}), 1.49-1.30(\mathrm{~m}, 6 \mathrm{H}), 1.13(\mathrm{~m}, 1 \mathrm{H}) .{ }^{13} \mathrm{C} \mathrm{NMR}(100 \mathrm{MHz}$, DMSO- $\left.d_{6}\right) \delta 176.00,175.90,173.60,172.80,171.56,171.42,141.02,134.62,133.63,131.16$, $128.93,127.92,125.72,123.75,59.22,53.00,51.00,47.00,35.00$. ESI-MS (-VE) $\mathrm{m} / z: 758.2$ $(\mathrm{M}-\mathrm{H})^{-}$. HR-ESI/APCI cacld for $\mathrm{C}_{40} \mathrm{H}_{47} \mathrm{~N}_{5} \mathrm{O}_{10} \mathrm{P}(\mathrm{M}-\mathrm{H})^{-}:$: 788.3060, Found: 788.3082.
\end{abstract}

\begin{abstract}
(9S,12E,15S,18S)-18-(2-Amino-2-oxoethyl)-15-[[(1-naphthalenylmethyl)amino] carbonyl]-8,17,20-trioxo-10-[4-(phosphonomethyl)phenyl]-7,10,16,19-tetraazaspiro[5.14] eicos-12-ene-9-acetic Acid (2f) and 9R,12E,15S,18S)-18-(2-Amino-2-oxoethyl)-15-[[(1naphthalenylmethyl)amino]carbonyl]-8,17,20-trioxo-10-[4-(phosphonomethyl) phenyl]-7,10,16,19-tetraazaspiro[5.14]eicos-12-ene-9-acetic Acid (2g)
\end{abstract}

Ring-closing metathesis of $\mathbf{2 4}$ followed by deprotection and HPLC purification as reported above for the conversion of $\mathbf{2 1}$ to $\mathbf{2 c}$ yielded macrocyclic final products as white powders in $56 \%$ combined yield from $24: 2 \mathbf{f}$ ( $15 \mathrm{mg}$, retention time: 26.6 minutes) and $2 \mathrm{~g}$ (3 $\mathrm{mg}$, retention time: 25.4 minutes) For $2 \mathbf{2 f}{ }^{1} \mathrm{H}$ NMR (400 MHz, acetone- $d_{6}$, with one drop $\left.\mathrm{D}_{2} \mathrm{O}\right) \delta 8.12(\mathrm{~d}, J$ 
$=7.2 \mathrm{~Hz}, 2 \mathrm{H}), 7.91(\mathrm{~d}, J=8.0 \mathrm{~Hz}, 1 \mathrm{H}), 7.83(\mathrm{~d}, J=8.4 \mathrm{~Hz}, 1 \mathrm{H}), 7.67-7.52(\mathrm{~m}, 5 \mathrm{H}), 7.46$ $(\mathrm{t}, J=7.6 \mathrm{~Hz}, 1 \mathrm{H}), 7.41(\mathrm{t}, J=9.6 \mathrm{~Hz}, 1 \mathrm{H}), 7.14(\mathrm{dd}, J=8.8,2.0 \mathrm{~Hz}, 2 \mathrm{H}), 6.82(\mathrm{~d}, J=8.8$ $\mathrm{Hz}, 2 \mathrm{H}), 5.62(\mathrm{~m}, 1 \mathrm{H}), 5.49(\mathrm{ddd}, J=15.8,9.2,4.8 \mathrm{~Hz}, 1 \mathrm{H}), 5.18(\mathrm{dd}, J=14.8,7.2 \mathrm{~Hz}, 1$ H), $4.90(\mathrm{t}, J=7.0 \mathrm{~Hz}, 1 \mathrm{H}), 4.72(\mathrm{~m}, 1 \mathrm{H}), 4.60(\mathrm{dd}, J=15.0,3.8 \mathrm{~Hz}, 1 \mathrm{H}), 4.33(\mathrm{~m}, 1 \mathrm{H})$, $3.92(\mathrm{~d}, J=17.2 \mathrm{~Hz}, 1 \mathrm{H}), 3.82(\mathrm{dd}, J=16.2,7.4 \mathrm{~Hz}, 1 \mathrm{H}), 2.97(\mathrm{~d}, J=20.8 \mathrm{~Hz}, 2 \mathrm{H}), 2.85(\mathrm{~d}$, $J=13.6 \mathrm{~Hz}, 1 \mathrm{H}), 2.63(\mathrm{dd}, J=15.6,4.4 \mathrm{~Hz}, 1 \mathrm{H}), 2.52(\mathrm{~d}, J=7.6 \mathrm{~Hz}, 2 \mathrm{H}), 2.46(\mathrm{dd}, J=15.6$, $8.0 \mathrm{~Hz}, 1 \mathrm{H}), 2.07(\mathrm{~m}, 1 \mathrm{H}), 1.88(\mathrm{~m}, 1 \mathrm{H}), 1.65(\mathrm{~m}, 1 \mathrm{H}), 1.56-1.40(\mathrm{~m}, 5 \mathrm{H}), 1.30(\mathrm{~m}, 1 \mathrm{H})$, $1.18-1.09$ (m, $2 \mathrm{H}) .{ }^{13} \mathrm{C}$ NMR $\left(100 \mathrm{MHz}, \mathrm{CDCl}_{3}\right) \delta 175.35,172.17,171.51,171.17,170.80$, 146.76, 134.56, 133.60, 131.20, 128.78, 127.88, 125.99, 123.89, 113.82, 59.06, 51.64, 46.14, 35.28, 34.14. MALDI-MS (+VE) $\mathrm{m} / \mathrm{z}: 813(\mathrm{M}+\mathrm{Na})^{+}$. HR-MALDI cacld for $\mathrm{C}_{39} \mathrm{H}_{47} \mathrm{~N}_{6} \mathrm{NaO}_{10} \mathrm{P}(\mathrm{M}+\mathrm{Na})^{+}$: 813.2984. Found: 813.3011. For 2g: ${ }^{1} \mathrm{H}$ NMR $(400 \mathrm{MHz}$, DMSO- $\left.d_{6}\right) \delta 8.32(\mathrm{t}, J=5.8 \mathrm{~Hz}, 1 \mathrm{H}), 8.18(\mathrm{~s}, 1 \mathrm{H}), 7.94(\mathrm{~m}, 1 \mathrm{H}), 7.86(\mathrm{~m}, 1 \mathrm{H}), 7.81(\mathrm{~d}, J=$ $8.4 \mathrm{~Hz}, 1 \mathrm{H}), 7.75$ (dd, $J=6.0,3.2 \mathrm{~Hz}, 1 \mathrm{H}), 7.49-7.44(\mathrm{~m}, 2 \mathrm{H}), 7.38-7.33(\mathrm{~m}, 3 \mathrm{H}), 7.20$ $(\mathrm{d}, J=7.6 \mathrm{~Hz}, 1 \mathrm{H}), 6.97(\mathrm{dd}, J=8.8,2.0 \mathrm{~Hz}, 2 \mathrm{H}), 6.86(\mathrm{~s}, 1 \mathrm{H}), 6.58(\mathrm{~d}, J=8.8 \mathrm{~Hz}, 2 \mathrm{H})$, $5.49(\mathrm{dt}, J=15.6,5.6 \mathrm{~Hz}, 1 \mathrm{H}), 5.32(\mathrm{~m}, 1 \mathrm{H}), 4.77(\mathrm{t}, J=7.6 \mathrm{~Hz}, 1 \mathrm{H}), 4.70(\mathrm{dd}, J=15.6,6.0$ $\mathrm{Hz}, 1 \mathrm{H}), 4.56(\mathrm{dd}, J=15.2,5.2 \mathrm{~Hz}, 1 \mathrm{H}), 4.46(\mathrm{dd}, J 14.0,6.0 \mathrm{~Hz}, 1 \mathrm{H}), 4.18(\mathrm{~m}, 1 \mathrm{H}), 3.83$ $(\mathrm{m}, 1 \mathrm{H}), 3.72(\mathrm{dd}, J=17.6,6.0 \mathrm{~Hz}, 1 \mathrm{H}), 2.93(\mathrm{dd}, J=16.0,6.8 \mathrm{~Hz}, 1 \mathrm{H}), 2.73(\mathrm{~d}, J=20.8$ $\mathrm{Hz}, 2 \mathrm{H}), 2.58-2.50(\mathrm{~m}, 2 \mathrm{H}), 2.37$ (dd, $J=15.8,6.2 \mathrm{~Hz}, 1 \mathrm{H}), 2.06(\mathrm{~m}, 2 \mathrm{H}), 1.82(\mathrm{~m}, 1 \mathrm{H})$, $1.67(\mathrm{~m}, 1 \mathrm{H}), 1.55-1.33(\mathrm{~m}, 6 \mathrm{H}), 1.16-1.08(\mathrm{~m}, 2 \mathrm{H}) .{ }^{13} \mathrm{C} \mathrm{NMR}\left(100 \mathrm{MHz}, \mathrm{CDCl}_{3}\right) \delta$ $174.32,172.90,172.71,171.97,171.38,171.09,146.70,134.74,133.62,131.15,128.91$, $127.75,126.04,125.34,123.81,122.33,112.66,59.78,50.03$. MALDI-MS (+VE) $\mathrm{m} / \mathrm{z}: 813$ $(\mathrm{M}+\mathrm{Na})^{+}$. HR-MALDI cacld for $\mathrm{C}_{39} \mathrm{H}_{47} \mathrm{~N}_{6} \mathrm{NaO}_{10} \mathrm{P}(\mathrm{M}+\mathrm{Na})^{+}:$813.2984, Found: 813.2988.

\section{Supplementary Material}

Refer to Web version on PubMed Central for supplementary material.

\section{Acknowledgments}

The authors wish to thank Drs. James A. Kelley and Christopher Lai of the Laboratory of Medicinal Chemistry, NCI, for FAB-MS data. This research was supported in part by the Intramural Research Program of the NIH, Center for Cancer Research, NCI-Frederick and the National Cancer Institute, National Institutes of Health, under contract N01CO-12400. The content of this publication does not necessarily reflect the views or policies of the Department of Health and Human Services, nor does mention of trade names, commercial products, or organizations imply endorsement by the U.S. Government.

\section{Abbreviations}

pTyr, phosphotyrosyl; $\mathrm{Ac}_{6} \mathrm{c}$, aminocyclohexanecarboxylic acid; $\mathrm{EDC} \cdot \mathrm{HCl},[1-(3-$ dimethylaminopropyl)-3-ethylcarbodiimide $\bullet \mathrm{HCl}$; HOAt, 1-hydroxy-7-azabenzotriazole.

\section{References and Notes}

1. Zhou J, Klaess T, Johnson KM, Giberson KM, Kozikowski AP. Bioorg. Med. Chem. Lett 2005;15:2461-2465. [PubMed: 15863297]

2. Ullrich T, Krich S, Binder D, Mereiter K, Anderson David J, Meyer Michael D, Pyerin M. J. Med. Chem 2002;45:4047-4054. [PubMed: 12190326]

3. Nam N-H, Ye G, Sun G, Parang K. J. Med. Chem 2004;47:3131-3141. [PubMed: 15163193]

4. Meyer JP, Collins N, Lung FD, Davis P, Zalewska T, Porreca F, Yamamura HI, Hruby VJ. J. Med. Chem 1994;37:3910-3917. [PubMed: 7966152]

5. Kossakowski J, Krawiecka M, Kuran B. Molecules 2006;11:615-626. [PubMed: 17971734]

6. Interpretation of entropy effects on the binding of conformationally restricted ligands must be done with caution. See: Martin SF. Preorganization in biological systems: are conformational constraints worth the energy? Pure Appl. Chem 2007;79:193-200. 
7. Dharmawardana PG, Peruzzi B, Giubellino A, Burke TR Jr. Bottaro DP. Anti-Cancer Drugs 2005;17:13-20. [PubMed: 16317285]

8. Rahuel J, Gay B, Erdmann D, Strauss A, Garcia-Echeverria C, Furet P, Caravatti G, Fretz H, Schoepfer J, Gruetter MG. Nat. Struct. Biology 1996;3:586-589.

9. Burke TR Jr. Int. J. Pept. Res. Therap 2006;12:33-48.

10. Gao Y, Wei C-Q, Burke TR Jr. Org. Lett 2001;3:1617-1620. [PubMed: 11405669]

11. Wei C-Q, Gao Y, Lee K, Guo R, Li B, Zhang M, Yang D, Burke TR Jr. J. Med. Chem 2003;46:244254. [PubMed: 12519063]

12. Shi Z-D, Wei C-Q, Lee K, Liu H, Zhang M, Araki T, Roberts LR, Worthy KM, Fisher RJ, Neel BG, Kelley JA, Yang D, Burke TR Jr. J. Med. Chem 2004;47:2166-2169. [PubMed: 15056012]

13. Oishi S, Karki RG, Kang S-U, Wang X, Worthy KM, Bindu LK, Nicklaus MC, Fisher RJ, Burke TR Jr. J. Med. Chem 2005;48:764-772. [PubMed: 15689160]

14. Oishi S, Shi Z-D, Worthy KM, Bindu LK, Fisher RJ, Burke TR Jr. ChemBioChem 2005;6:668-674. [PubMed: 15719347]

15. Rodriguez A, Miller DD, Jacckson RFW. Org. Biomol. Chem 2003;1:973-977. [PubMed: 12929636]

16. Adamczyk M, Johnson DD, Reddy RE. Tetrahedron: Asymmetry 1999;10:775-781.

17. Burke TR Jr. Liu DG, Gao Y. J. Org. Chem 2000;65:6288-6291. [PubMed: 10987981]

18. Jaime-Figueroa S, Liu Y, Muchowski JM, Putman DG. Tetrahedron Lett 1998;39:1313-1316.

19. Pridgen LN, Abdel-Magid AF, Lantos I, Shilcrat S, Eggleston DS. J. Org. Chem 1993;58:5107-5117.

20. (a) Scholl M, Ding S, Lee CW, Grubbs RH. Org. Lett 1999;1:953-956. [PubMed: 10823227] (b)

Blackwell HE, Sadowsky JD, Howard RJ, Sampson JN, Chao JA, Steinmetz WE, O'Leary DJ, Grubbs RH. J. Org. Chem 2001;66:5291-5302. [PubMed: 11485448] (c) Grubbs RH. Tetrahedron 2004;60:7117-7140.

21. Liu F, Worthy KM, Bindu L, Giubellino A, Bottaro DP, Fisher RJ, Burke TR Jr. Org. Biomol. Chem 2007;5:367-372. [PubMed: 17205182]

22. Phan J, Shi Z-D, Burke Terrence R Jr. Waugh David S. J. Mo;. Biol 2005;353(1):104-15.

23. Myszka DG, Morton TA. Trends Biochem. Sci 1998;23:149-150. [PubMed: 9584619] 
<smiles>NC(=O)C[C@H](NC(=O)C1(NC(=O)[C@H](CC(=O)O)Cc2ccc(CP(=O)(O)O)cc2)CCCCCCCCCC1=O)C(=O)NCc1cccc2ccccc12</smiles>

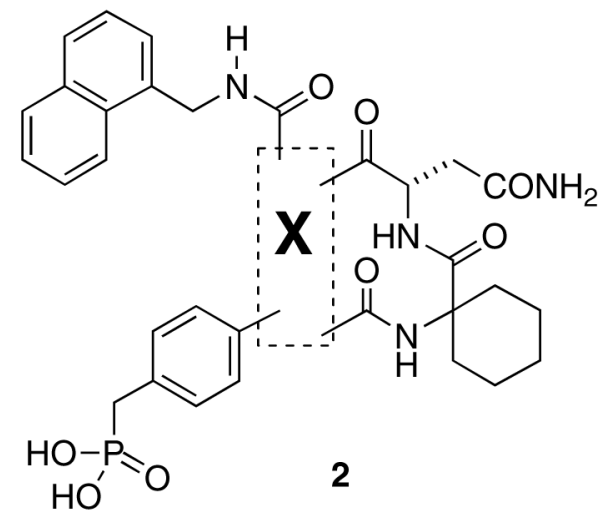

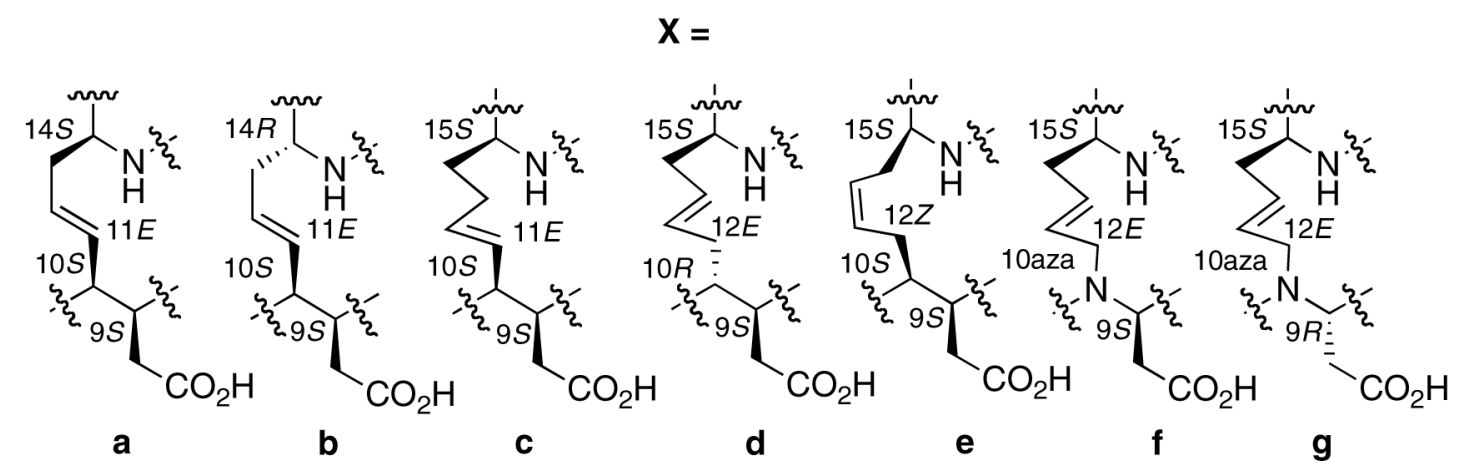

Figure 1.

Structure of open-chain 1 and macrocyclic variants 2 . 


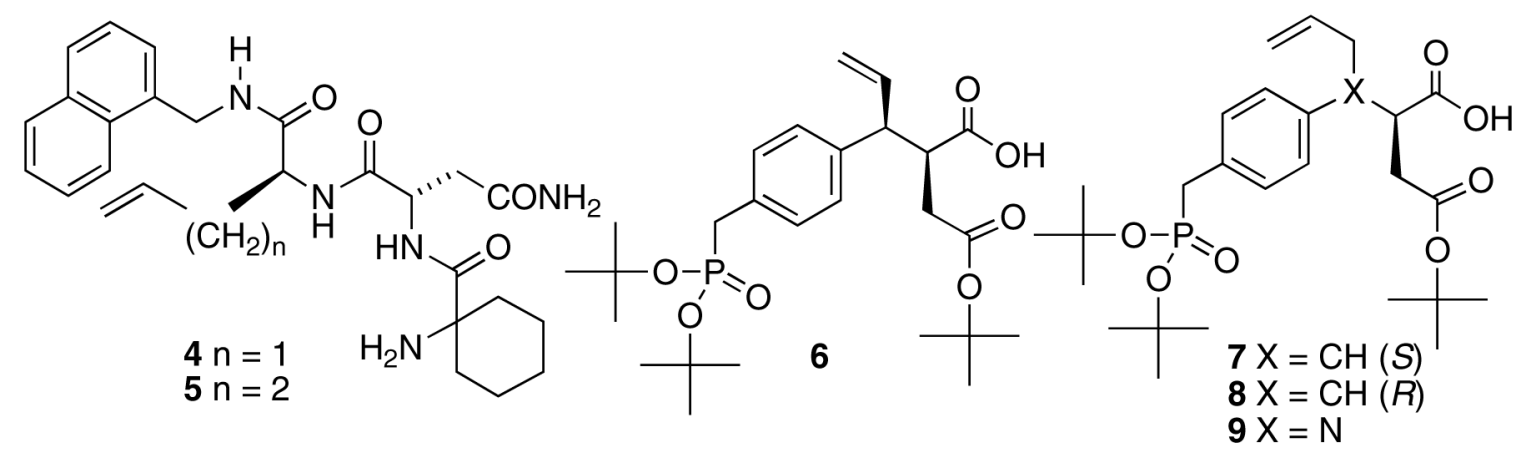

Figure 2.

Synthetic building blocks for the synthesis of macrocycles 2 . 


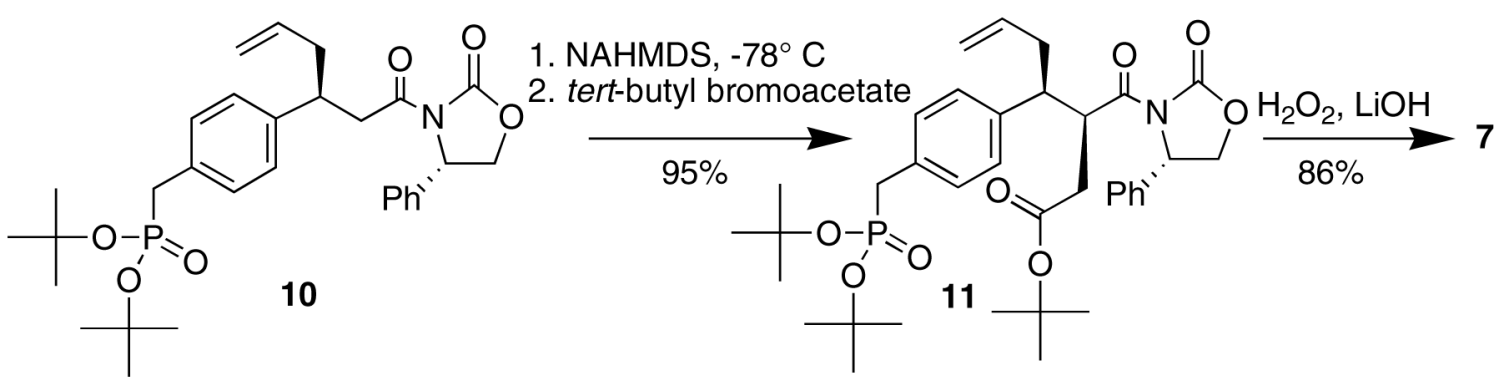

Scheme 1. 


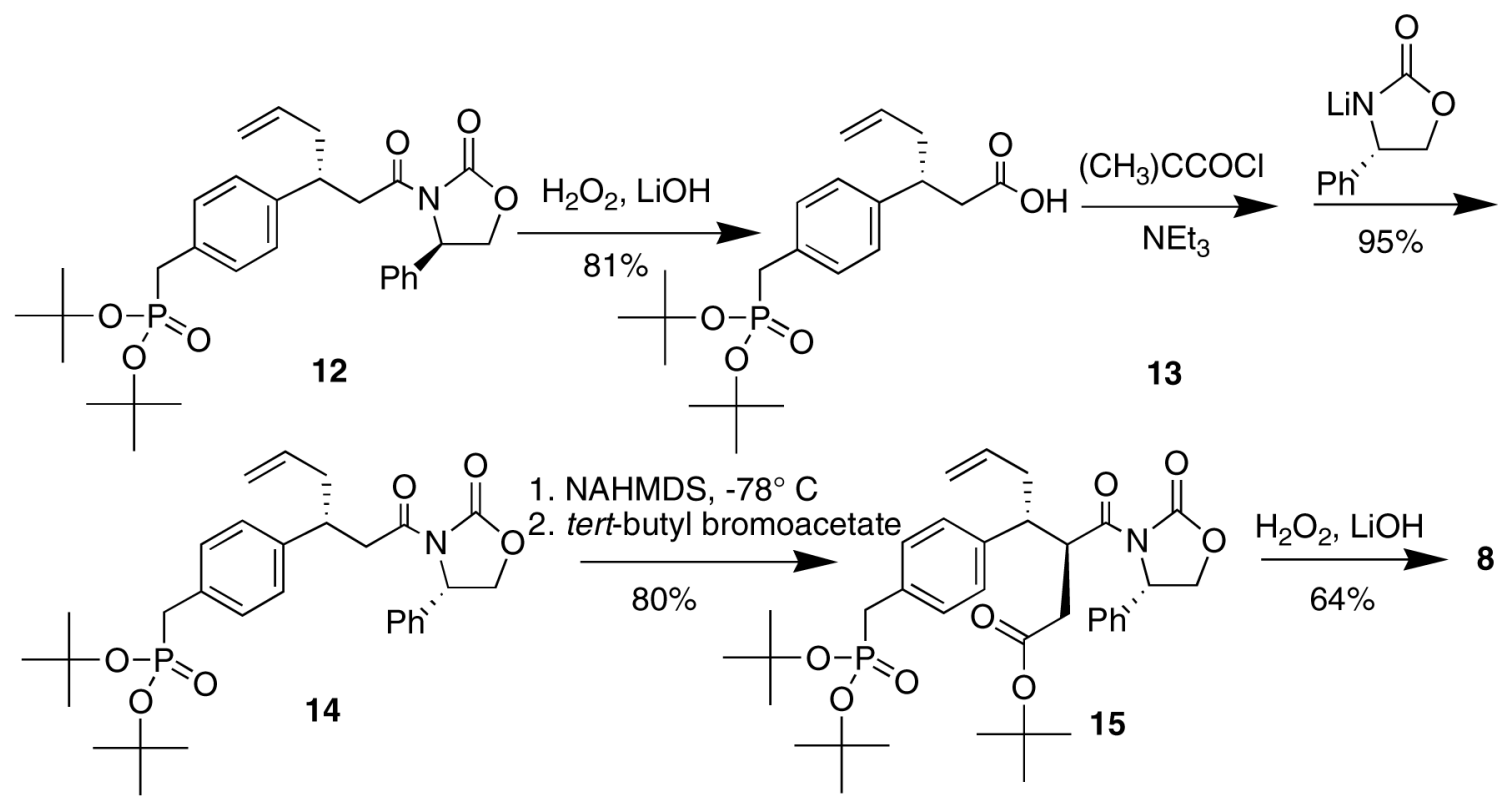

Scheme 2. 


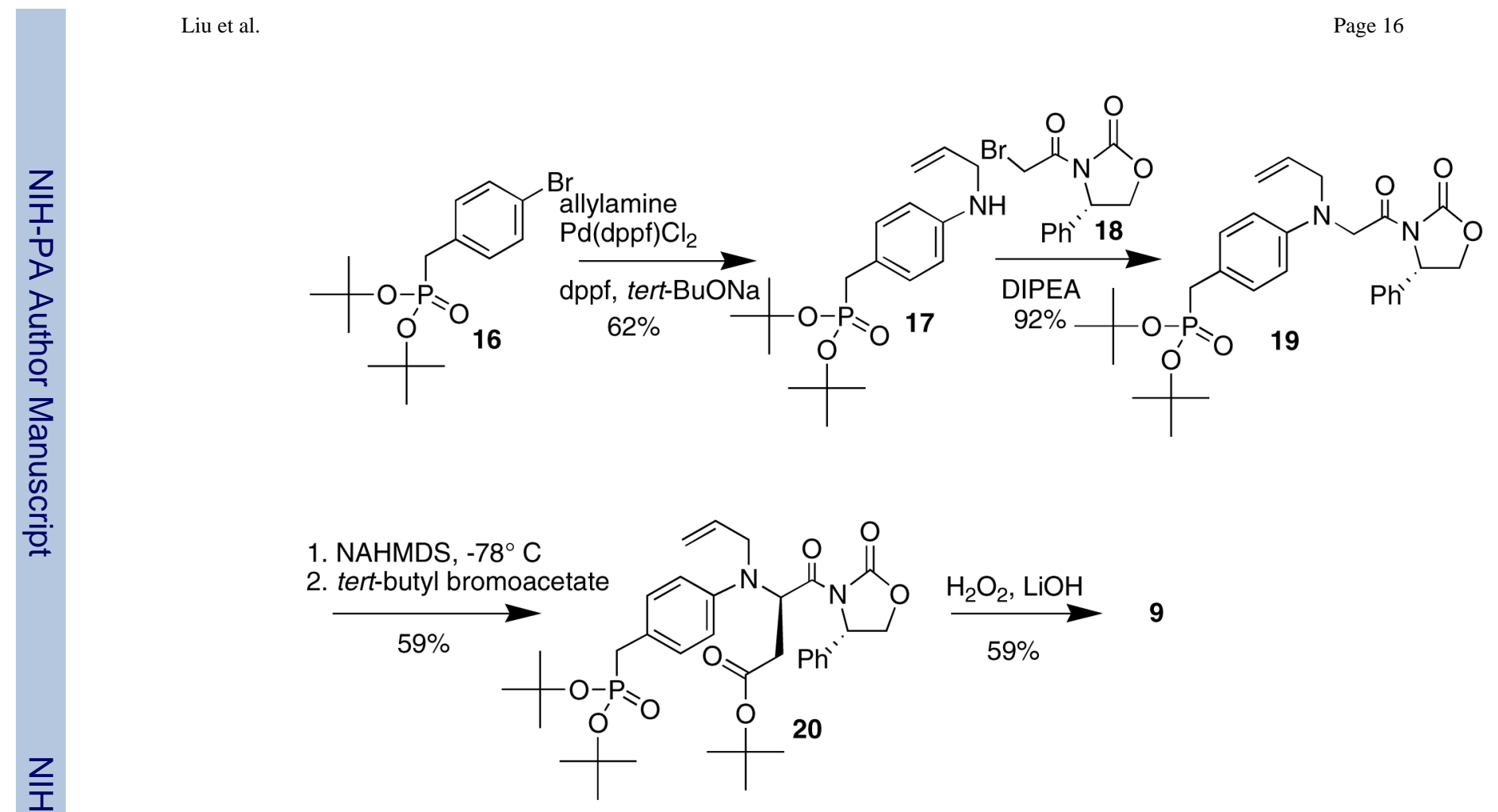

Scheme 3. 


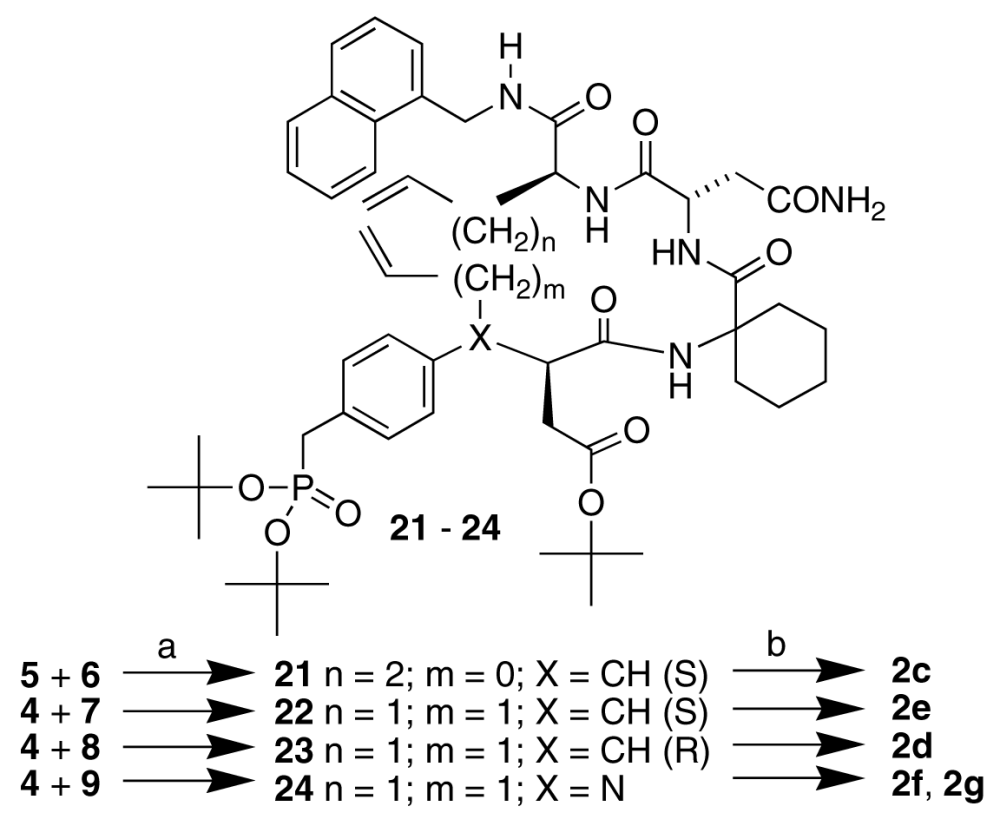

Scheme 4.

(a) 1, HOAt, EDCI, DIPEA, DMF, $50{ }^{\circ} \mathrm{C}, 36$ h; yields: 21, $21 \%$; $22,45 \% ; \mathbf{2 3}, 38 \%$; 24, $65 \%$. (b) [1] [( $\left.\left.\mathrm{PCy}_{3}\right)\left(\mathrm{Im}(\mathrm{Mes})_{2}\right) \mathrm{Ru}=\mathrm{CHPh}\right], \mathrm{CH}_{2} \mathrm{Cl}_{2}$, reflux, $48 \mathrm{~h}$; [2] TFA, $\mathrm{H}_{2} \mathrm{O}$ and $\mathrm{HSiEt}_{3}, 1 \mathrm{~h}$; yields: $2 \mathrm{c}, 12 \%$; $2 \mathrm{e}, 50 \%$; $2 \mathrm{~d}, 30 \%$; $2 \mathrm{f}$ and $\mathbf{2 g}, 56 \%$ combined (5: 1 ratio). 
Table 1

Grb2 SH2 Domain-Binding Affinities of Synthetic Macrocycles. ${ }^{a}$

\begin{tabular}{|c|c|c|c|}
\hline Compound & $\mathbf{K}_{\mathbf{D}}(\mathbf{n M}) \pm \mathbf{s d}$ & Compound & $\mathbf{K}_{\mathbf{D}}(\mathbf{n M}) \pm \mathbf{s d}$ \\
\hline $\mathbf{2 a}$ & $22.7 \pm 0.5^{b}$ & $\mathbf{2 e}$ & $38 \pm 15,{ }^{d f}$ \\
\hline $\mathbf{2 b}$ & $55 \pm 1.0^{b}$ & $\mathbf{2 f}$ & $287 \pm 64{ }^{c f}$ \\
\hline $\mathbf{2 c}$ & $20 \pm 5,{ }^{c e}$ & $\mathbf{2 g}$ & $>10,000,{ }^{c e}$ \\
\hline $\mathbf{2 d}$ & $70 \pm 24,{ }^{d f}$ & & \\
\hline
\end{tabular}

${ }^{a}$ Performed using surface plasmon resonance as decribed in the Experimental Section.

${ }^{b}$ Values previously reported in reference 14 .

${ }^{c}$ Amine-coupled surface.

$d_{\text {Biotin-capture surface. }}$

${ }^{e}$ Biacore S51 instrument.

$f_{\text {Biacore T100 instrument. }}$ 